Caroline Rondina Salzano de Oliveira

Potenciais evocados auditivos e esclerose múltipla

Dissertação apresentada à Faculdade de Medicina da Universidade de São Paulo para obtenção do título de Mestre em Ciências

Área de concentração: Comunicação Humana Orientadora: Profa Dra Carla Gentile Matas

São Paulo 
Caroline Rondina Salzano de Oliveira

\section{Potenciais evocados auditivos e esclerose múltipla}

Dissertação apresentada à Faculdade de

Medicina da Universidade de São Paulo para obtenção do título de Mestre em Ciências

Área de concentração: Comunicação Humana Orientadora: Profa Dra Carla Gentile Matas

São Paulo

2008 
Dados Internacionais de Catalogação na Publicação (CIP) Preparada pela Biblioteca da

Faculdade de Medicina da Universidade de São Paulo

Creprodução autorizada pelo autor

Oliveira, Caroline Rondina Salzano de Potenciais evocados auditivos e esclerose múltipla / Caroline Rondina Salzano de Oliveira. -- São Paulo, 2008.

Dissertação(mestrado)--Faculdade de Medicina da Universidade de São Paulo. Departamento de Fisioterapia, Fonoaudiologia e Terapia Ocupacional.

Área de concentração: Comunicação Humana.

Orientadora: Carla Gentile Matas.

Descritores: 1.Potenciais evocados auditivos 2.Potenciais evocados auditivos do tronco encefálico 3.Potencial evocado P300 4.Esclerose múltipla

USP/FM/SBD-216/08 


\section{DEDICATÓRIA}

Dedico este trabalho ao meu filho João Ricardo por ser um estímulo que me impulsiona a buscar vida nova a cada dia. Meu muito obrigado por ter compreendido, mesmo que de forma inconsciente, minha ausência em seus primeiros meses de vida. 


\section{AGRADECIMENTOS}

A minha querida e admirável orientadora $\operatorname{Prof}^{a}$ Dr $^{\mathrm{a}}$ CARLA GENTILE MATAS pelo carinho, incentivo, apoio, presteza no auxílio às atividades, discussões sobre o andamento e normatização desta Dissertação e por não poupar esforços com seu exemplo e profissionalismo, bem como o amor e dedicação em momentos especiais de minha vida.

As professoras doutoras ELIANE SCHOCHAT e RENATA MOTA MAMEDE CARVALLO pelo apoio prestado ao longo do curso, especialmente no momento da qualificação.

A doutora IVONE FERREIRA NEVES que contribuiu para a conclusão desta Dissertação, especialmente no momento da qualificação.

A Associação dos Portadores de Esclerose Múltipla de Brasília por ter viabilizado o contato com os indivíduos da pesquisa desta Dissertação.

As colegas de LIF pela espontaneidade e alegria na troca de informações e materiais com amizade e solidariedade. 
Aos portadores de Esclerose Múltipla que aceitaram e se disponibilizaram a participar da pesquisa.

Aos meus pais HEBE e MÁRIO JÚLIO pela dedicação, esforço, amor, carinho e compreensão ao longo de toda a minha vida e, principalmente, por estar sempre presentes. compartilhando minhas vitórias, conquistas e apoiando nos meus momentos mais importantes.

A minha avó HEBE por não medir esforços, sempre solidária ao meu lado .

Ao meu esposo RICARDO pelo amor, paciência e compreensão de minha ausência, auxiliando-me no percurso desta conquista.

E, principalmente, a Deus por me conceder a Graça da saúde e capacidade intelectual para desenvolver este trabalho, bem como pela oportunidade do privilégio em compartilhar experiências com pessoas.tão especiais. 


\section{NORMATIZAÇÃO ADOTADA}

Esta dissertação está de acordo com as seguintes normas, em vigor no momento desta publicação:

Referências: adaptado de International Committee of Medical Journals Editors (Vancouver)

Universidade de São Paulo. Faculdade de Medicina. Serviço de Biblioteca e Documentação. Guia de apresentação de dissertações, teses e monografias. Elaborado por Anneliese Carneiro da Cunha, Maria Julia de A. L. Freddi, Maria F. Crestana, Marinalva de Souza Aragão, Suely Campos Cardoso, Valéria Vilhena. 2a. ed. São Paulo: Serviço de Biblioteca e Documentação; 2005.

Abreviaturas dos títulos dos periódicos de acordo com List of Journals Indexed in Index Medicus. 


\section{SUMÁRIO}

Lista de Tabela

Lista de Quadros

Lista de Abreviaturas

Lista de Símbolos e Siglas

Resumo

Summary

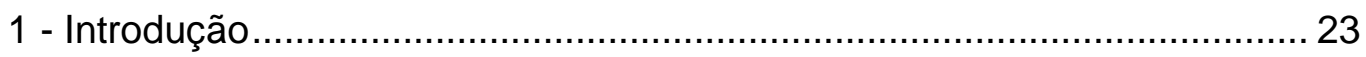

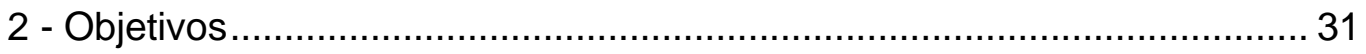

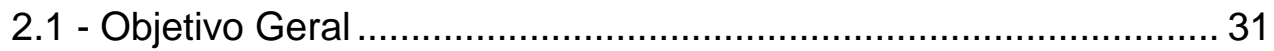

2.2 - Objetivos Específicos................................................... 31

3 - Revisão de Literatura ..................................................................... 33

3.1 - Potenciais Evocados Auditivos ................................................. 33

3.1.1 - Potencial Evocado Auditivo de Tronco Encefálico.................. 36

3.1.2 - Potenciais Evocados Auditivos de Média Latência................. 39

3.1.3 - Potenciais Evocados Auditivos de Longa Latência ............... 42

3.2 - Achados eletrofisiológicos da audição em Esclerose Múltipla..... 47

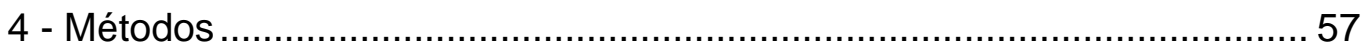

4.1 - Casuística ................................................................. 57

4.1 .1 - Critérios de Inclusão ...................................................... 59

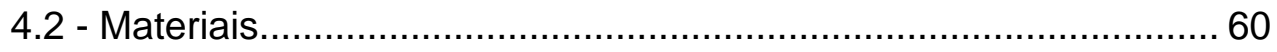

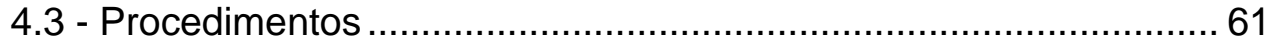

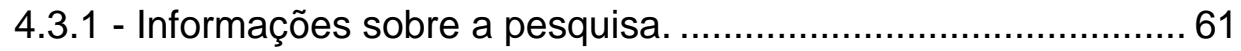

4.3.2 - Coleta da história clínica. ................................................ 62

4.3.3 - Avaliações eletroacústicas, comportamentais, e eletrofisiológicas da audição................................................... 62

4.4 - Critérios de avaliação dos resultados .....................................6 66

4.5 - Método estatístico ............................................................. 72 


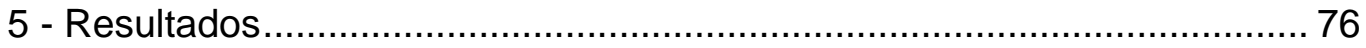

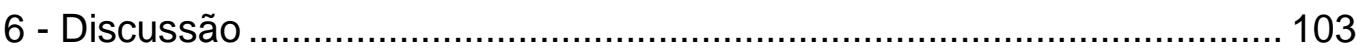

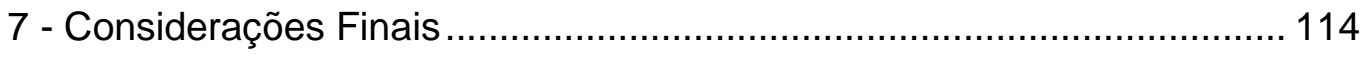

8 - Conclusão

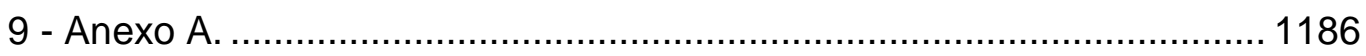

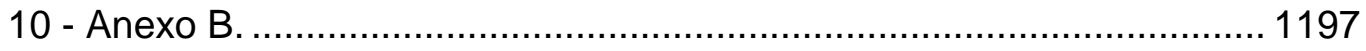

11 - Referências Bibliográficas ........................................................... 123 


\section{LISTA DE TABELAS}

TABELA 1 - Comparação dos valores médios das latências absolutas das ondas I, III e V e dos interpicos I-III, III-V, e I-V em ms entre as orelhas direita e esquerda no PEATE, para o grupo controle. .p.78

TABELA 2 - Comparação dos valores médios das latências absolutas das ondas I, III, e V e dos interpicos I-III, III-V, e I-V em ms entre as orelhas direita e esquerda no PEATE, para o grupo pesquisa

TABELA 3 - Comparação dos valores médios das latências absolutas das ondas I, III e V e dos interpicos I-III, III-V, e I-V em ms, entre os grupos controle e pesquisa. p. 80

TABELA 4 - Distribuição da ocorrência de resultados normais e alterados no PEATE, nos grupos controle e pesquisa p.81

TABELA 5 - Distribuição dos tipos de alterações encontradas no PEATE, nos grupos controle e pesquisa p.82

TABELA 6 - Comparação dos valores médios das latências da onda Na em ms, entre as modalidades C3/A1 e C3/A2, e entre C4/A1 e C4/A2 do PEAML, no grupo controle. p.83

TABELA 7 - Comparação dos valores médios das latências da onda Pa em ms, entre as modalidades C3/A1 e C3/A2, e entre C4/A1 e C4/A2 do PEAML, no grupo controle. p.84

TABELA 8 - Comparação dos valores médios das latências da onda $\mathrm{Na}$ em ms, entre as modalidades C3/A1 e C3/A2, e entre C4/A1 e C4/A2 do PEAML, no grupo pesquisa. p.85 
TABELA 9 - Comparação dos valores médios das latências da onda Pa em ms, entre as modalidades C3/A1 e C3/A2, e entre C4/A1 e C4/A2 do PEAML, no grupo pesquisa. p.86

TABELA 10 - Comparação dos valores médios das amplitudes $\mathrm{Na}-\mathrm{Pa}$ em $\mu \mathrm{v}$ entre as modalidades C3/A1 e C3/A2, e entre C4/A1 e C4/A2 do PEAML, no grupo controle p. 87

TABELA 11 - Comparação dos valores médios das amplitudes $\mathrm{Na}$-Pa em $\mu \mathrm{v}$ entre as modalidades C3/A1 e C3/A2, e entre C4/A1 e C4/A2 do PEAML, no grupo pesquisa. .p.88

TABELA 12 - Comparação dos valores médios das amplitudes $\mathrm{Na}$-Pa em $\mu \mathrm{v}$ entre as modalidades C3/A1 e C4/A1, e entre C3/A2 e C4/A2 do PEAML, no grupo controle.... p.89

TABELA 13 - Comparação dos valores médios das amplitudes $\mathrm{Na}$-Pa em $\mu \mathrm{v}$ entre as modalidades C3/A1 e C4/A1, e entre C3/A2 e C4/A2 do PEAML, no grupo pesquisa. .p.90

TABELA 14 - Comparação dos valores médios das amplitudes Na-Pa em $\mu \mathrm{v}$ nas modalidades C3/A1, C3/A2, C4/A1, C4/A2 do PEAML, entre os grupos controle e pesquisa p.91

TABELA 15 - Distribuição da ocorrência de resultados normais e alterados para a latência da onda $\mathrm{Na}$ do PEAML, nos grupos controle e pesquisa p.92

TABELA 16 - Distribuição da ocorrência de resultados normais e alterados para a latência da onda Pa do PEAML, nos grupos controle e pesquisa. .p.92

TABELA 17 - Distribuição da ocorrência de resultados normais e alterados para a amplitude $\mathrm{Na}-\mathrm{Pa}$ do PEAML, nos grupos controle e pesquisa. p.93 
TABELA 18 - Distribuição dos tipos de alterações encontradas para a amplitude $\mathrm{Na}-\mathrm{Pa}$ do PEAML, nos grupos controle e pesquisa.............................................................. .95

TABELA 19- Comparação dos valores médios das latências do P300 em ms entre as orelhas direita e esquerda, no grupo

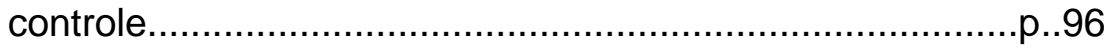

TABELA 20 - Comparação dos valores médios das latências do P300 em ms entre as orelhas direita e esquerda, no grupo

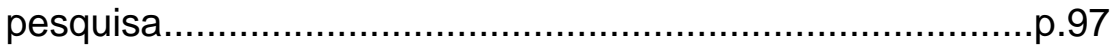

TABELA 21 - Comparação dos valores médios das latências do P300 em ms entre os grupos controle e pesquisa...........................p.98

TABELA 22 - Distribuição da ocorrência de resultados normais e alterados no $\mathrm{P} 300$, nos grupos controle e pesquisa. .p.99

TABELA 23 - Distribuição dos tipos de alterações encontradas no P300, nos grupos controle e pesquisa 


\section{LISTA DE QUADROS}

Quadro 1: Padrão de normalidade dos valores de latências e interpicos do PEATE, para indivíduos acima de 24 meses, proposto pelo manual do usuário do ATCplus.....................................p.68

Quadro 2: Padrão de normalidade dos valores de latências das ondas $\mathrm{Na}$ e Pa do PEAML.........................................................p. 69

Quadro 3: Padrão de normalidade dos valores de latência da onda P300, para cada faixa etária, proposto por McPherson (1996).........p.69 


\section{LISTA DE ABREVIATURAS}

$\begin{array}{ll}\text { et al. } & \text { e outros } \\ \mathrm{dB} & \text { decibel } \\ \mathrm{Hz} & \text { Hertz } \\ \text { kohms } & \text { kilo ohms } \\ \mathrm{ms} & \text { milissegundo } \\ \mu & \text { microvolt } \\ \mathrm{p} . & \text { página } \\ \mathrm{s} & \text { segundo }\end{array}$




\section{LISTA DE SÍMBOLOS e SIGLAS}

\begin{tabular}{|c|c|}
\hline A1 & Mastóide esquerda \\
\hline A2 & Mastóide direita \\
\hline ABR & Auditory Brainstem Response \\
\hline BAEP & Brainstem Auditory Evoked Potential \\
\hline BAER & Brainstem Auditory- Evoked Response \\
\hline BB & Broad Band \\
\hline BERA & Brainstem Evoked Response Audiometry \\
\hline $\mathrm{BIC}$ & Binaural interaction component \\
\hline BSER & Brainstem Evoked Response \\
\hline C3 & Junção têmporo-parietal esquerda \\
\hline C4 & Junção têmporo-parietal direita \\
\hline \multirow[t]{2}{*}{ CAPPesq } & Comissão de Ética para Análise de Projetos de \\
\hline & Pesquisa \\
\hline $\mathrm{Cz}$ & Vértex \\
\hline EEG & Eletroencefalograma \\
\hline EM & Esclerose Múltipla \\
\hline ERP & Event-Related Potentials \\
\hline $\mathrm{F}$ & Feminino \\
\hline \multirow[t]{2}{*}{ FMUSP } & Faculdade de Medicina da Universidade de São \\
\hline & Paulo \\
\hline IEC & International Electrotechnical Commission \\
\hline IRF & Índice de Reconhecimento de Fala \\
\hline
\end{tabular}




$\begin{array}{ll}\text { LLR } & \text { Long Latency Response } \\ \text { LRF } & \text { Limiar de Reconhecimento de Fala } \\ \text { M } & \text { Masculino } \\ \text { MLAEP } & \text { Middle Latency Auditory Evoked Potential } \\ \text { MLR } & \text { Middle Latency Response } \\ \text { MMF } & \text { Magnetoencephalographic Measurements of } \\ & \text { Mismatch Field } \\ \text { NA } & \text { Nível de audição } \\ \text { OD } & \text { Orelha direita } \\ \text { OE } & \text { Orelha esquerda } \\ \text { PEALL } & \text { Potencial Evocado Auditivo de Longa Latência } \\ \text { PEAML } & \text { Potencial Evocado Auditivo de Média Latência } \\ \text { PEA } & \text { Potenciais Evocados Auditivos } \\ \text { PEATE } & \text { Potencial Evocado Auditivo de Tronco Encefálico } \\ \text { P300 } & \begin{array}{l}\text { Sotencial Cognitivo } \\ \text { USP }\end{array}\end{array}$




\section{Resumo}




\section{RESUMO}

Oliveira CRS. POTENCIAIS EVOCADOS AUDITIVOS E ESCLEROSE MÚLTIPLA. São Paulo: Faculdade de Medicina, Universidade de São Paulo; 2007.

INTRODUÇÃO: A Esclerose Múltipla é uma doença desmielinizante e autoimune, na qual ocorre a destruição da bainha de mielina por autoanticorpos. Esta destruição causa uma diminuição na velocidade de condução do impulso nervoso alterando, assim, as funções cerebral e neural. Para ocorrer o funcionamento adequado do sistema auditivo, tanto na sua porção periférica quanto na central há necessidade que o mesmo esteja íntegro. OBJETIVO: Este estudo tem como objetivo verificar a ocorrência de alterações nos potenciais evocados auditivos de curta (PEATE), média (PEAML) e longa (P300) latências em adultos audiologicamente normais com diagnóstico de Esclerose Múltipla do tipo remitente recorrente ou surto remissivo. MÉTODO: Para o grupo controle foram avaliados 25 indivíduos com histórico de desenvolvimento neurológico normal e sem queixa de zumbido, sendo 19 do gênero feminino e seis do masculino, com idade variando entre 25 e 55 anos (média de 35,16 anos de idade). Para o grupo pesquisa foram avaliados 25 indivíduos com Esclerose Múltipla do tipo remitente-recorrente ou surto-remissivo, seis do gênero masculino e 19 do feminino, com idades entre 25 e 53 anos (média de 34,88 anos de idade). Todos os indivíduos participantes da pesquisa realizaram audiometria tonal e vocal, medidas de imitância acústica e os potenciais 
evocados auditivos de curta, média e longa latências. RESULTADOS: Os resultados demonstraram ocorrência de alterações nos potenciais evocados auditivos de tronco encefálico e de média latência e no potencial cognitivo, em indivíduos com Esclerose Múltipla. Com relação ao potencial evocado auditivo de tronco encefálico, verificou-se aumento de latência das ondas III e $\mathrm{V}$ e dos interpicos I-III e I-V, sugerindo alteração de tronco encefálico baixo. No que diz respeito ao potencial evocado auditivo de média latência observou-se atraso nas latências das ondas $\mathrm{Na}$ e $\mathrm{Pa}$ e, para o potencial cognitivo, evidenciou-se aumento da latência do P300. Conclusão: Indivíduos com Esclerose Múltipla do tipo remitente recorrente apresentam alterações eletrofisiológicas observadas nos resultados dos potenciais evocados auditivos de curta e média latências e no potencial cognitivo, sugerindo comprometimento em diferentes locais do sistema nervoso auditivo central.

Descritores: potenciais evocados auditivos, potenciais evocados auditivos de tronco encefálico, potencial evocado P300, esclerose múltipla. 


\section{SUMMARY}

INTRODUCTION: The Multiple Sclerosis is a demyelinating disease and autoimmune, which is the destruction of the myelin sheath of a selfantibodies. This destruction causes a decrease in impulse driving speed of nervous changing thus the brain and neural functions. To place the proper functioning of the auditory system, both in its peripheral portion as the central need that it is full. PURPOSE: This study aims to determine the occurrency of changes in auditory evoked potentials of short (PEATE), middle (PEAML) and long (P300) latencies in adults audiologically normal diagnosed with Multiple Sclerosis remitting type of applicant or remissive outbreak. METHOD: For the control group were evaluated 25 individuals with a history of normal neurological development and without complaint from tinnitus, and 19 females and six males, with ages ranging between 25 and 55 years (average of 35.16 years of age). To search the group were evaluated 25 individuals with Multiple Sclerosis-remitting type of applicant or flareremissive, six males and 19 females, aged between 25 and 53 years (average of 34.88 years of age). All individuals participating in the search conducted tone audiometry and speech, acoustic immitance measures brainstem auditory evoked potential, middle latency response and cognitive potential RESULTS: The results showed occurrencies of changes in brainstem auditory evoked potential and middle latency and cognitive potential in individuals with Multiple Sclerosis. Regarding the potential of brain stem auditory evoked, there was an increase in latency wave III and V and interpeaks I-III and IV, suggesting change in brainstem down. Regarding 
the auditory evoked potential of average latency there was delay in latencies of $\mathrm{Na}$ and $\mathrm{Pa}$ waves, and the potential for cognitive, showed an increase of latency of P300. Conclusion: Individuals with multiple sclerosis relapsing remitting type of applicant presents electrophysiological changes seen in the results of sound evoked short and middle latency and the potential cognitive suggesting impairment from different parts of the central auditory nervous system.

Descriptors: auditory evoked potentials, auditory brain stem evoked potentials, P300 event-related potentials, multiple sclerosis. 


\section{Introdução}




\section{1 - INTRODUÇÃO}

A Esclerose Múltipla (EM) ou Doença Desmielinizante, descoberta pelo francês Jean Charcot em 1860, é uma doença produzida pela destruição da bainha de mielina por auto-anticorpos. A mielina envolve e isola eletricamente os axônios, permitindo que os impulsos nervosos trafeguem em alta velocidade dentro do parênquima encefálico. Portanto, as alterações das funções encefálicas são decorrentes da diminuição da velocidade dos impulsos nervosos provocada pela destruição do envoltório mielínico.

A mielina é uma substância constituída por proteínas e gorduras que ajudam na condução das mensagens que controlam todos os movimentos conscientes e inconscientes do organismo. A EM recebe este nome devido à forma que se instala no organismo, pois a bainha de mielina até um ponto específico possui a capacidade de reconstituição, reparando a área lesada. Com o surgimento de novos surtos a evolução é inevitável, ocorrendo seu agravamento progressivo, e as áreas comprometidas vão perdendo a capacidade de reparação e sofrendo um processo de endurecimento. Desta forma, aparecem pequenas e inúmeras placas esclerosantes que podem surgir em qualquer lugar do Sistema Nervoso Central, fazendo com que estudiosos denominassem esta doença de Esclerose Múltipla. 
A Associação Brasileira de Esclerose Múltipla realizou um simpósio em 1995, no qual foram apresentados dados estatísticos da incidência da doença em países de clima temperado, sendo que mulheres com idade entre 20 a 40 anos foram as mais afetadas. A evolução da doença é lenta e progressiva, com períodos de exacerbação e remissão dos sintomas. No norte da Europa, norte dos Estados Unidos e Canadá a prevalência está em aproximadamente 50/100.000 (Martyn, 1991; Callegaro et al., 1992). No Brasil, estudos como o de Oliveira et al. (1999) não confirmam estes dados, porém com menor prevalência, de aproximadamente 5/100.000.

Frequentemente, a primeira lesão a se manifestar clinicamente pode não ser a primeira ocorrida, pois qualquer queixa subjetiva ou qualquer sinal objetivo pode evidenciar o manifesto clínico da doença, que causa uma série de crises nas quais os sintomas podem ser discretos ou intensos, aparecendo e desaparecendo. Os sintomas mais encontrados na EM são debilidade de uma ou mais extremidades (braços e pernas); fadigabilidade e fraqueza dos membros; neurite ótica, podendo ocasionar perda visual unilateral; incoordenação motora; rápidas contrações musculares involuntárias; parestesia; alterações esfincterianas, causando retenção e/ou incontinência; vertigens; perda de audição; dores faciais, decorrente de nevralgia do trigêmeo; dores nos braços, nas pernas e no tronco e impotência sexual (Santos, 1997). 
As lesões da EM causam uma grande variedade de sinais e sintomas iniciais que aparecem isolados ou de maneira combinada. A progressão da doença e o surgimento dos sinais variam de minutos a dias. Em pacientes crônicos, os sintomas podem aumentar gradualmente durante meses. Quanto à recuperação dos sintomas há uma grande variação, mas em geral ocorre de duas a oito semanas após um ataque agudo.

Em 1996 Lublin e Reingold classificaram a EM da seguinte forma:

- Surto Remissivo ou Remitente Recorrente - os surtos de intensificação dos sintomas ocorrem a cada período de um a três anos seguidos por um período de diminuição dos sintomas. Estes surtos, quando ocorrem, podem durar de semanas a meses e então desaparecem gradualmente. Os sinais e sintomas podem se acumular de um surto para outro. Em 75\% das pessoas com EM, a doença manifesta-se no início do tipo surto-remissivo, e em $25 \%$ de outros tipos. Destes $25 \%$, metade após algum tempo será enquadrado na classificação surto-remissivo.

-Progressiva Primária - depois do aparecimento dos primeiros sintomas, a deterioração ocorre sem um período de diminuição dos mesmos. Cerca de $15 \%$ das pessoas começam com este padrão da doença.

-Progressiva Secundária - aparece em pessoas com o tipo remitente - recorrente após anos de diagnóstico da doença, onde os surtos que aparecem repentinamente entram em um estágio de contínua deterioração.

- Surto Progressivo ou Recaída Progressiva - apresenta-se de forma 
similar à progressiva primária, adicionada de repentinos episódios de novos sintomas ou períodos de extinção total dos mesmos. É a forma mais rara da doença, ocorrendo em aproximadamente $10 \%$ das pessoas com EM.

A EM, embora descrita e estudada há mais de 150 anos, não possui causas definidas, somente hipóteses, sendo que se destacam mais os estudos dirigidos às causas imunológica e viral. Existem muitas pesquisas em andamento direcionadas ao indivíduo portador e também ao ambiente onde ele vive. As hipóteses etiológicas levantadas permanecem ainda sem resposta, pois quando se pensa em causa viral fica a dúvida de quais ou quantos vírus estariam envolvidos, ou se seria um único vírus, e como seria transmitido. Com relação à hereditariedade, permanece a questão se ocorre um favorecimento para o surgimento da doença ou, ao contrário, se há alguma proteção do indivíduo contra ela. Diante desta ausência de respostas, os estudiosos continuam procurando explicações para o surgimento da doença.

A EM pode lesionar o Sistema Nervoso Central e deve-se lembrar que a sensibilidade auditiva depende da integridade do mesmo. 
A literatura evidencia que um diagnóstico audiológico baseado apenas em uma avaliação audiológica convencional em pacientes com EM não é eficiente, visto que muitas alterações ocorrem ao longo da via auditiva central (Collard et al., 1969; Noffsinger et al., 1972; Fisher et al., 1984; Mustillo, 1984; Jerger et al., 1986).

Jerger e Jerger (1989) sugeriram uma configuração audiológica específica para os pacientes com EM, ou seja, presença de perda auditiva neurossensorial leve com curva descendente ou, algumas vezes, perda auditiva isolada em uma única freqüência.

Para avaliar o sistema auditivo periférico e central em adultos deve-se utilizar como procedimentos as audiometrias tonal e vocal, medidas de imitancia acústica e avaliação eletrofisiológica da audição por meio dos potenciais evocados auditivos, sendo estes últimos os mais eficazes por serem métodos objetivos, isto é, que não dependem do paciente para obtenção das respostas.

A pesquisa dos Potenciais Evocados Auditivos (PEA) avaliam a atividade neuroelétrica na via auditiva do nervo auditivo ao córtex cerebral, frente a um estímulo ou evento acústico (Junqueira e Frizzo, 2002). 
Dentre os PEA precoces, o mais utilizado na prática clínica é o Potencial Evocado Auditivo de Tronco Encefálico (PEATE) devido à sua reprodutibilidade e propriedade de localização. O PEATE avalia a integridade da via auditiva desde o nervo auditivo até o tronco encefálico, ocorre de zero a oito milissegundos (ms) após a apresentação do estímulo acústico, e é constituído por sete ondas geradas por uma ou mais estruturas ao longo da via auditiva (Matas et al., 1998; Durrant e Ferraro, 2001).

O Potencial Evocado Auditivo de Média Latência (PEAML) reflete a ativação de várias estruturas sub-corticais incluindo estruturas auditivas do tronco encefálico médio, formação reticular e divisões multi-sensoriais do tálamo; ocorre entre 10 e 80 ms após o início do estímulo acústico, sendo constituído por uma série de ondas que aparecem após o PEATE e antecedem os potenciais tardios (Musiek, 1991).

Os Potenciais Evocados Auditivos de Longa Latência (PEALL) ou tardios aparecem após o PEAML e ocorrem entre 70 e 500 ms após a apresentação do estímulo acústico, sendo utilizados clinicamente como auxílio no diagnóstico de alterações específicas do desenvolvimento da via auditiva central. 
Em pacientes com EM, a evolução da doença está relacionada ao aumento do número e da extensão das placas escleróticas ao longo da via auditiva, o que altera significativamente a integridade da mesma. Levandose em consideração este aspecto e devido à escassez de pesquisas correlacionando os PEA e a EM em pacientes clinicamente estáveis (tipo remitente recorrente ou surto remissivo), torna-se importante conhecer o funcionamento do sistema nervoso auditivo central, desde o tronco encefálico até o córtex auditivo, neste grupo. 


\section{Objetivos}




\section{2 - OBJETIVOS}

\section{1 - Objetivo Geral}

Este estudo teve como objetivo analisar e comparar os potenciais evocados auditivos de curta (PEATE), média (PEAML) e longa (P300) latências em adultos audiologicamente normais com diagnóstico de Esclerose Múltipla do tipo remitente recorrente ou surto remissivo.

\section{2 - Objetivos Específicos}

- Analisar e comparar os resultados do PEATE obtidos em indivíduos com Esclerose Múltipla do tipo remitente recorrente com os obtidos em indivíduos normais.

- Analisar e comparar os resultados do PEAML obtidos em indivíduos com Esclerose Múltipla do tipo remitente recorrente com os obtidos em indivíduos normais.

- Analisar e comparar os resultados do P300 obtidos em indivíduos com Esclerose Múltipla do tipo remitente recorrente com os obtidos em indivíduos normais. 


\section{Revisão de Literatura}




\section{3 - REVISÃO DE LITERATURA}

A revisão de literatura apresentada a seguir considerou os trabalhos pertinentes ao assunto em questão, respeitando os termos que foram originalmente utilizados pelos autores.

Optou-se por dividir este capítulo em duas partes distintas, a saber:

3.1 - Potenciais Evocados Auditivos:

3.1.1 - Potencial Evocado Auditivo de Tronco Encefálico;

3.1.2 - Potenciais Evocados Auditivos de Média Latência;

3.1.3 - Potenciais Evocados Auditivos de Longa Latência;

3.2 - Achados eletrofisiológicos da audição em Esclerose Múltipla.

\section{1 - Potenciais Evocados Auditivos}

Um potencial evocado é gerado por uma série de mudanças elétricas que podem ocorrer tanto no sistema nervoso periférico como central, estando correlacionadas às vias sensoriais. Portanto, denomina-se potencial evocado auditivo (PEA) as mudanças elétricas no sistema nervoso auditivo decorrentes de uma estimulação acústica. 
McPherson e Starr (1993) afirmaram que os potenciais evocados podem ser caracterizados de acordo com o tempo em que ocorrem, conhecido como latência, sendo que os aumentos das respostas são evidências objetivas de problemas clínicos e/ou sub-clínicos.

O primeiro estudo que descreveu os potenciais evocados no ser humano, provenientes de uma estimulação acústica, foi o de Davis et al. em 1939, que enfatizou que estas respostas eram modificações do traçado do eletroencefalograma e que apresentavam como provável origem o córtex cerebral.

Os Potenciais Evocados Auditivos (PEA) têm sido muito utilizados em Neurociência por fornecerem uma medida objetiva sobre a integridade do sistema auditivo como um todo.

Os PEA foram classificados em sensoriais ou exógenos, e em endógenos ou cognitivos. Os potenciais sensoriais ou exógenos são determinados pelas características físicas e temporais dos estímulos, estando diretamente relacionados a eles. Os potenciais endógenos ou cognitivos variam de indivíduo para indivíduo, dependendo tanto das tarefas realizadas pelos mesmos como também do conteúdo dos estímulos que está diretamente correlacionado às atividades do processamento cerebral (Donchin et al., 1978; Hyllard e Picton, 1987; Chiappa, 1997). 
Segundo Stach (1998), o PEA é uma resposta eletrofisiológica frente ao som e pode ser classificada de acordo com a latência: latência breve ou curta correspondendo à eletrococleografia e Audiometria de Tronco Encefálico (Auditory Brainstem Response - ABR), latência média (Middle Latency Response - MLR) e longa latência (Long Latency Response - LLR), este último incluindo o P300, sendo utilizados para determinar o limiar de detecção do sinal acústico e inferir sobre a integridade funcional e estrutural dos componentes neurais das vias auditivas (Kraus et al., 1999).

Os PEA avaliam a via auditiva, desde o nervo auditivo até o córtex cerebral, e refletem a atividade sincrônica destas estruturas frente a um estímulo ou evento acústico (Schochat, 2004). Para a captação e registro dos PEA são utilizados eletrodos de ouro, prata ou cobre, fixados no couro cabeludo, fronte, lóbulos das orelhas ou mastóides com pasta abrasiva que facilita a condução elétrica. As respostas elétricas captadas passam por uma filtragem e amplificação sendo posteriormente promediadas (separadas dos artefatos e somadas), permitindo assim, sua visualização em forma de ondas no computador (Junqueira e Frizzo, 2002). 
Alguns fatores como o nível de consciência do indivíduo durante o exame podem influenciar a captação dos PEA. Geralmente solicita-se ao indivíduo cooperação, sendo que o mesmo deve permanecer quieto e relativamente imóvel durante o exame, pois movimentos corpóreos principalmente da região cervical e facial podem acarretar no surgimento de potenciais miogênicos e/ou artefatos elétricos (Ferraro e Durrant, 1999).

A integridade funcional e estrutural dos componentes do sistema nervoso auditivo, bem como a determinação do limiar de detecção do sinal acústico são as principais funções dos PEA (Kraus et al., 1999).

\subsection{1 - Potencial Evocado Auditivo de Tronco Encefálico}

O Potencial Evocado Auditivo de Tronco Encefálico (PEATE) é o PEA de curta latência ou precoce mais conhecido e utilizado na prática clinica, devido à sua reprodutibilidade e propriedades de localização. Ocorre nos primeiros 10 ms após a estimulação acústica, podendo também ser denominado de ABR ou, ainda, Brainstem Evoked Response Audiometry (BERA). Este potencial é composto por sete ondas, sendo as maiores em

amplitude e, conseqüentemente, mais visíveis as ondas I, III e V, geradas por uma ou mais estruturas ao longo da via auditiva no tronco encefálico. 
Segundo Möller et al. (1981), os geradores destas ondas são: onda I - porção distal ao tronco encefálico do nervo auditivo, onda II - porção proximal ao tronco encefálico do nervo auditivo, onda III - núcleo coclear, onda IV - complexo olivar superior, onda V - lemnisco lateral, onda VI colículo inferior, onda VII - corpo geniculado medial.

Pesquisando a integridade da via auditiva deve-se utilizar alta intensidade, não variável, o que permite a avaliação da via auditiva no tronco encefálico e a identificação de possíveis alterações neste trajeto. Devem ser identificadas as ondas I, III e V, analisando seus tempos de latência absoluta e os intervalos de ocorrência entre elas (I-III, III-V e I-V). Torna-se importante, também, a observação da relação das amplitudes das ondas $\mathrm{V}$ e I e a comparação entre orelhas.

Os PEA são importantes para avaliar a sincronia neural, que é uma habilidade do sistema nervoso central em responder sincronicamente a uma estimulação sonora, ativando um grande número de neurônios ao mesmo tempo. Quando existe integridade deste sistema, é possível registrar respostas neurais a estímulos apresentados em vários níveis de intensidade (Hood, 1995). 
Matas et al. (1998) descreveram as principais aplicações clínicas da ABR: avaliação da função auditiva em recém -nascidos e em crianças difíceis de serem avaliadas por outros procedimentos de rotina, avaliação da maturação do sistema auditivo central, detecção de tumores do nervo acústico, diagnóstico topográfico de distúrbios da fossa posterior, entre outras.

Musiek et al. (1999) ressaltaram a utilização de algumas medidas da ABR auxiliando no neurodiagnóstico, como as análises da latência absoluta da onda $V$, da diferença interaural da latência da onda $V$, e dos interpicos IIII, I-V, e III-V, enfatizando que a presença ou ausência destas respostas, num determinado tempo de latência, permite verificar a existência de alterações tanto estruturais como funcionais que possam vir a interferir na transmissão do estímulo acústico desde o nervo auditivo até o tronco encefálico.

O exame deve ser realizado num ambiente isolado elétrica e acusticamente para evitar presença de artefatos que dificultem a obtenção e a análise dos dados. 


\subsection{2 - Potenciais Evocados Auditivos de Média Latência}

Os Potenciais Evocados Auditivos de Média Latência (PEAML), também denominado de Middle Latency Response (MLR), foram inicialmente descritos por Geisler et al. (1958), que visualizaram uma onda negativa em torno de $20 \mathrm{~ms}$ seguida de um pico positivo em aproximadamente 30ms. Posteriormente, alguns pesquisadores incluíram outros picos negativos e positivos como fazendo parte deste potencial.

Musiek e Geurkink em 1981, descreveram o primeiro gerador do potencial evocado auditivo de média latência, o córtex auditivo.

Özdamar e Kraus (1983) registraram simultaneamente as ondas da ABR e da MLR para facilitar a comparação das duas respostas evocadas. Verificaram que, para intensidades médias e fortes, as ondas $\mathrm{Na}$ e $\mathrm{Pa}$ da MLR e a onda $V$ da ABR foram obtidas confiavelmente em todos os indivíduos avaliados, porém em intensidades mais fracas houve melhor visualização da onda V. Concluíram, portanto, que o teste mais indicado para avaliar a sensibilidade auditiva é a ABR, enquanto que a MLR pode ser mais fidedigna na avaliação dos distúrbios de processamento auditivo ou neurológico. 
Os PEAML foram definidos como uma série de ondas positivas e negativas que ocorrem após o PEATE e antecedem os potenciais evocados auditivos tardios, com latências entre 10 e 80 ms após o início da estimulação acústica (Ruth e Lambert, 1991).

Devido à localização de seus geradores, as respostas de média latência atingem os níveis de normalidade de indivíduos adultos entre 08 a 10 anos de idade, não podendo serem utilizadas precocemente na identificação de deficiências auditivas (Hall, 1992).

Dentre as aplicações clínicas do PEAML tem-se a avaliação do funcionamento do implante coclear, além do mesmo poder ser utilizado para auxiliar no diagnóstico do funcionamento da via auditiva, na localização de lesões e até mesmo no monitoramento intraoperatório (Chermak e Musiek, 1997; Kraus et al., 1999). Quando utilizada no diagnóstico de lesões neurológicas, as ondas obtidas podem apresentar amplitudes diminuídas.

Os geradores que contribuem para a formação deste potencial incluem a via auditiva tálamo-cortical, a formação reticular mesencefálica e o colículo inferior (Kraus et al, 1999), e o córtex auditivo (Musiek e Geurkink, 1981). 
Na MLR é possível reconhecer quatro ondas positivas e três negativas, mas somente as primeiras ondas $\mathrm{Na}, \mathrm{Pa}, \mathrm{Nb}$ e $\mathrm{Pb}$ são analisadas por serem as mais consistentes, estáveis e de maior amplitude, sendo que a amplitude é a medida mais confiável para fins diagnósticos (Musiek e Lee, 2001).

Schochat (2003) afirmou que, devido à localização dos geradores do PEAML, este é considerado um dos melhores exames para avaliar o sistema nervoso auditivo central e os distúrbios do processamento auditivo. À exceção do potencial evocado auditivo de longa latência, os PEA não dependem das habilidades lingüísticas e cognitivas do indivíduo.

Um estudo realizado por Schochat et al. (2004) avaliou as medidas de latências e amplitudes da onda $\mathrm{Pa}$, considerando três cortes para a análise de normalidade (30\%, 40\% e 50\% de diferença entre a amplitude da onda Pa em relação ao mesmo eletrodo, mas variando a orelha; e da amplitude da onda $\mathrm{Pa}$, considerando a mesma orelha e variando o eletrodo). Nos resultados pode-se observar que o corte de $30 \%$ foi o melhor para avaliar o efeito de eletrodo e o efeito de orelha. As autoras verificaram, ainda, que o efeito de orelha foi o mais efetivo para avaliar os transtornos de processamento auditivo, enquanto que o efeito de eletrodo foi mais sensível para evidenciar algum tipo de lesão. 
Sabe-se ainda que este potencial pode ser uma ferramenta muito útil para a reabllitação de pacientes, auxiliando em técnicas que visam direcionar uma melhor terapia de linguagem (Schochat, 2004)

\subsection{3 - Potenciais Evocados Auditivos de Longa Latência}

Os Potenciais Evocados Auditivos de Longa Latência (PEALL) ou Respostas de Longa Latência (Long Latency Response-LLR) têm sido muito estudados nas áreas de neurologia, psiquiatria, psicologia e na audiologia. Os PEALL, também denominados potenciais tardios e/ou relacionados a eventos, refletem atividades responsáveis por funções de discriminação, integração e atenção. Dentre os PEALL, o mais utilizado é o Potencial Cognitivo ou P300, que surge em torno de 300 ms após a estimulação acústica.

Sutton et al. em 1965 observaram pela primeira vez uma resposta tardia em aproximadamente 300ms após o início do estimulo acústico, captada em humanos, e sugeriram que esta refletia dois tipos de influência: uma exógena e relacionada à natureza do estímulo, e outra endógena, relacionada à reação do indivíduo frente ao estímulo. 
Revisando várias pesquisas que estudaram a relação entre o P300 e as desordens cognitivas, Polich (1991) discutiu e ressaltou vários fatores que podem interferir na variabilidade das respostas do P300, visando uma maior precisão destas respostas e uma melhor interpretação dos resultados. Levantou variáveis do indivíduo, como idade, gênero, ingestão de alimentos antes do exame, habilidade cognitiva e temperatura corporal, alertando que estes fatores podem afetar a amplitude e/ou latência da onda P300. Enfatizou também que alguns parâmetros utilizados para a avaliação, como o tipo de estímulo acústico e a tarefa realizada, também podem influenciar nos componentes do P300. Concluiu que o P300 é um instrumento útil no diagnóstico de disfunções cognitivas, desde que sejam controladas algumas variáveis, a fim de que se possa produzir maior sensibilidade e utilidade para este potencial.

Os PEALL foram definidos, segundo Ruth e Lambert (1991), como respostas que surgem após a MLR registradas entre 80 a 750 ms após a estimulação acústica.

$\mathrm{Na}$ avaliação do P300, a latência parece ser um indicador mais confiável que a amplitude, visto que esta última é difícil de ser alterada em função da atenção. Para Picton (1992), quando as amplitudes do P300 encontrarem-se diminuídas ou latências atrasadas, este dado pode ser sugestivo de um déficit no processamento cognitivo. 
Várias pesquisas foram realizadas com sujeitos portadores de lesões corticais visando uma determinação específica dos sítios geradores deste potencial, porém parece existir uma sobreposição de fontes geradoras, de forma geral. Pode-se afirmar que, para a geração do P300, existe a contribuição do córtex frontal, córtex centroparietal e do hipocampo (McPherson, 1996).

Segundo Kraus e McGee (1999), os PEALL evidenciam atividades do tálamo e do córtex, que são estruturas responsáveis por funções de discriminação, integração e atenção. As respostas deste potencial independem dos potenciais anteriores. Uma das características é que são pouco afetados pelas propriedades físicas do estímulo e, em contrapartida, são mais afetados pelo uso funcional que um indivíduo faz do estímulo. Este potencial é eliciado por um paradigma raro (paradigma "oddball" ou paradigma do alvo), no qual o indivíduo deve identificar o estímulo raro que ocorre dentro de uma série de estímulos freqüentes. Estes autores enfatizaram, ainda, a importância do P300 nos estudos das funções cognitivas de atenção e dos processos que envolvem a discriminação auditiva, memória e perspectiva semântica. 
Sendo assim, autores enfatizam que o P300 é um potencial tardio e endógeno, pois necessita de atenção, discriminação auditiva, memória e perspectiva semântica para sua geração, podendo apresentar-se alterado por uma variedade de distúrbios que afetam a cognição (Kraus e McGee, 1999; Munhoz et al, 2000).

Um estudo realizado por Colafêmina et al. (2000) visou estabelecer padrões de normalidade, analisando as latências e amplitudes dos componentes do PEALL em 20 indivíduos com idades entre 21 e 35 anos, sendo 10 do gênero masculino e 10 do gênero feminino. Todos deveriam ser otologicamente normais e não poderiam apresentar queixas relacionadas a alterações neurológicas e de aprendizagem. Os valores de latência e amplitude obtidos foram semelhantes aos estabelecidos na literatura, sendo verificadas diferenças significantes entre os gêneros masculino e feminino com relação às latências dos componentes N1, P2 e N2 e a amplitude do componente N1. 
Frizzo et al. (2001), levando em consideração as diferenças funcionais entre os hemisférios cerebrais, realizaram um estudo para verificar a ocorrência de possíveis diferenças entre os PEALL dos hemisférios direito e esquerdo. Para análise das respostas levaram em consideração os valores de latência e amplitudes, sendo verificada diferença em indivíduos do gênero masculino apenas para o componente P2. Frente a estes resultados enfatizaram a necessidade de pesquisas futuras que tenham como objetivo verificar a ocorrência de diferenças eletrofisiológicas entre os hemisférios.

Dentre as vantagens clínicas na utilização dos PEALL, Cone-Wesson e Wunderlich (2003) enfatizaram que os potenciais corticais podem ser eliciados por sons complexos como a fala, podendo ser utilizados na avaliação da sua discriminação e percepção.

Segundo Schochat (2004), o P300 é considerado um potencial endógeno, pois só poderá ser gerado se o indivíduo for capaz de focalizar a atenção num estímulo raro e discriminá-lo no meio de uma série de estímulos freqüentes. A justificativa para o aparecimento do P300 baseia-se no fato do sistema auditivo habituar-se a ouvir o estímulo freqüente, sendo que ao ouvir o estímulo raro o sistema auditivo responde com uma maior quantidade de descargas neuronais, gerando uma onda maior em amplitude denominada P300. 
A grande vantagem dos PEA, quando comparados a outros métodos neurocognitivos, é que permitem registrar a ativação neuronal associada ao processamento cerebral, tornando possível avaliar áreas cerebrais ativadas durante tarefas cognitivas de processamento (Santos et al., 2006).

\section{2 - Achados eletrofisiológicos da audição em Esclerose Múltipla.}

A Esclerose Múltipla (EM), doença desmielinizante e autoimune na qual ocorre a destruição da bainha de mielina por auto-anticorpos, pode lesionar o Sistema Nervoso Central, afetando também o Sistema Nervoso Auditivo Central. Melaragno (1992) relatou ser pouco freqüente o aparecimento de placas desmielinizantes no VIII nervo, sendo raro o aparecimento de deficiência auditiva nestes casos.

Diversos estudos enfatizaram que apenas uma avaliação audiológica convencional para se diagnosticar distúrbios auditivos em pacientes com EM não é eficiente, visto que muitas alterações ocorrem ao longo da via auditiva central. Portanto, torna-se imprescindível a utilização dos métodos eletrofisiológicos de audição que avaliam o sistema auditivo central. (Collard et al.,1969; Noffsinger et al., 1972; Fisher et al., 1984; Mustillo, 1984; Jerger et al. 1986). 
Newton et al. (1989), em seus estudos, encontraram uma incidência de $57 \%$ de alterações nos potenciais cognitivos que incluíam atraso nas latências das ondas e ausência de morfologia característica.

Giesser et al. (1992) observaram um atraso na latência do P300 correlacionada a um declínio cognitivo em diversas populações, tais como demência, traumatismo craniano, tumores cerebrais, EM e Parkinson.

Gil et al. (1992) realizaram estudo com portadores de EM e encontraram, como alteração mais freqüente, o aumento da latência do P300, correlacionando esta alteração com os resultados obtidos nos testes neuropsicológicos.

Dijk et al. (1992) encontraram diferenças nos potenciais evocados relacionados a eventos em um grupo de 30 portadores de $E M$, sendo que 15,6\% apresentaram ausência de picos das ondas nos potenciais avaliados. 
Celebisoy et al. (1996), em um estudo com 30 indivíduos com EM utilizando as medidas eletrofisiológicas para a avaliação da audição Brainstem Auditory Evoked Potential e Middle Latency Auditory Evoked Potential (BAEP e MLAEP), verificaram que 18 indivíduos apresentaram alteração no BAEP, 22 apresentaram alteração no MLAEP e 15 alteração nos dois potenciais. Os autores puderam concluir que os dois PEA utilizados de forma combinada são bastante sensíveis para a detecção de alterações na via auditiva em indivíduos com EM.

Foram encontradas evidências de alterações no BAEPs, mais especificamente na porção distal do nervo auditivo, em pacientes com EM sem perda auditiva, sendo comprovadas pela imagem de ressonância magnética (Bergamaschi et al., 1997).

Existem evidências de que as alterações cognitivas podem acometer pacientes com EM. Estudos neuropsicológicos como os de Rao et al. (1991) e Fischer (2001) indicaram disfunções cognitivas em 54 a 65\% destes pacientes, sendo que os mesmos podem apresentar alterações na memória, atenção, fluência verbal, execução de tarefas e percepção visual. 
Palace (2001) realizou um estudo sobre os exames necessários para o diagnóstico da EM e afirmou que a ABR é um teste que muitas vezes é dispensado por vários centros de diagnóstico por apresentar uma menor sensibilidade na detecção de alterações em pacientes com EM. Afirmou ser um exame pouco específico para esta doença, uma vez que avalia a via auditiva apenas até o tronco encefálico, não detectando lesões em outras áreas que participam dos processos auditivos. Destacou, também, que a realização da $A B R$ e de outros potenciais como um todo, bem como a análise dos resultados destes potenciais exigem uma boa especialização técnica.

A avaliação da latência e amplitude do P300, bem como a de outros potenciais permitem, por sua vez, relacionar graus distintos de comprometimento cognitivo com as diferentes formas evolutivas da EM, assim como com a progressão da mesma (Landete e Casanova, 2001).

Santos et al. (2003) avaliaram a incidência de alterações auditivas e nos PEATE em 20 indivíduos do gênero feminino e 9 do masculino, com diagnóstico definido de EM, sem sinais clínicos ou de alterações à ressonância nuclear magnética de acometimento do tronco encefálico. Todos os indivíduos realizaram a avaliação audiológica e a pesquisa dos PEATE. Para a análise da morfologia das ondas utilizou-se a classificação proposta por Jerger (1986): Tipo I: resposta normal, todas as ondas presentes com latências e interpicos normais; Tipo II: prolongamento do 
interpico I-V; Tipo III: degradação da forma das ondas, morfologia pobre, picos de difícil identificação e/ou amplitudes diminuídas, e/ou razões de amplitude anormais; Tipo IV: desaparecimento ou ausência das últimas ondas, estando as primeiras ondas presentes com latência normais; Tipo V: resposta extremamente anormal, apresentando somente a onda I normal. Dos 58 PEATE realizados encontrou-se 55\% classificados como tipo I (resposta normal) na classificação de Jerger, em ambos os sexos. Considerando-se as alterações obtidas no PEATE dos indivíduos portadores de EM, 45\% apresentaram os tipos II, III, IV ou V da classificação proposta por Jerger. Os resultados obtidos mostraram a existência de alterações em $60 \%$ dos indivíduos do gênero feminino e 56\% do masculino, totalizando $58,62 \%$ do total de indivíduos avaliados. Os achados deste estudo enfatizaram a relevância da realização dos PEATE em casos com suspeita clínica de doenças desmielinizantes e, principalmente, naqueles com diagnóstico definido de EM. Os tipos de alterações encontradas foram prejuízo na morfologia das ondas, aumento dos interpicos I-V, presença somente da onda I ou ausência das últimas ondas sendo que as primeiras apresentavam latência absoluta normal. 
Um estudo realizado no Japão por Kurokawa et al. (2003) ressaltou a importância da eletrofisiologia da audição no diagnóstico e no acompanhamento de indivíduos com EM. Este estudo foi realizado com 73 pacientes caucasianos com diagnóstico de EM, dos quais 34,3\% apresentaram algum tipo de alteração nos BAEP. Os autores enfatizaram a importância de incluir o P300 na bateria de exames para diagnóstico e acompanhamento da evolução da EM.

Singhal e Fowler (2004) estudaram o caso de um paciente com EM, realizando os PEA com a presença de um componente binaural (BIC). Sugeriu a utilização de um componente binaural na realização dos potenciais evocados (ABR, MLR e LLR) como representações dos processamentos que envolvem a via auditiva, e destacou que as características do BIC sugerem uma interação dos potenciais com fenômenos psicofisiológicos, como o desenvolvimento e envelhecimento. A autora ressaltou que a $A B R$ é um dos potenciais mais consistentes para a realização binaural e que este potencial adiciona fatores que podem contribuir para o BIC em potenciais mais tardios. O BIC só pode ser realizado em pessoas após os 09 anos de idade, demonstrando ser uma medida promissora de maturação cerebral. Este estudo ressaltou, ainda, a importância da investigação de mais estudos utilizando este componente binaural, para que o mesmo possa ser empregado no diagnóstico clínico. 
Gonzáles-Rosa et al. (2006) realizaram o P300 em pacientes com EM de diversos tipos, observando que este PEA é sensível o bastante para verificar alterações cognitivas que não podem ser tratadas farmacologicamente e nem por terapias neuropsicológicas.

Schochat et al. (2006) realizaram um estudo de caso em paciente com EM com queixa de dificuldade de conversar em ambientes ruidosos e desconforto auditivo frente a sons intensos. Na avaliação deste paciente foram utilizados os PEATE, PEAML e P300, antes e após terapia medicamentosa com corticoesteróides. Antes do tratamento medicamentoso, os resultados do PEATE foram compatíveis com normalidade na orelha esquerda e alteração na via auditiva em tronco encefálico baixo à direita (presença da onda I com latência absoluta dentro da normalidade, ausência da onda III e presença da onda $\mathrm{V}$ com latência absoluta aumentada). No PEAML foi observada a presença dos efeitos orelha e eletrodo, e o P300 encontrava-se normal. Após tratamento medicamentoso, observou-se uma melhora parcial na latência absoluta da Onda $V$ e, no PEAML, um aumento na amplitude da onda $\mathrm{Pa}$. Neste caso, os exames que avaliaram a função central da audição e o PEATE foram sensíveis para identificar o local da lesão (tronco encefálico), demonstrando estarem de acordo com as queixas apresentadas pelo paciente. 
Na EM, as avaliações eletrofisiológicas do Sistema Nervoso Central, realizadas pelos potenciais evocados visuais, auditivos de curta latência e somatossensitivos, estão bem estabelecidas. Os PEA relacionados a eventos têm sido amplamente estudados devido à sua correlação com aspectos cognitivos, indicando uma integridade das vias neurofisiológicas relacionadas com a informação sensorial endógena. As alterações encontradas nestes potenciais são definidas pelo prolongamento das ondas ou pela ausência de formação dos picos característicos. (Santos, 2006)

Um estudo prospectivo do P300 realizado por Magnano et al. (2006) enfatizou que a realização do P300 é um diferencial clínico em pacientes com EM, e que este potencial tem se mostrado extremamente eficaz na detecção de disfunções cognitivas. Os autores ressaltaram que tal fato aumenta as possibilidades de uma intervenção neuropsicológica visando a reabilitação cognitiva do paciente com EM.

Santos et al. (2006) realizaram um estudo utilizando o potencial evocado auditivo de longa latência relacionado a evento, estando presente em $60 \%$ dos indivíduos com EM quando foi utilizado um protocolo de estimulação auditiva com variação de duração, e em $45 \%$ no protocolo de estimulação auditiva com variação de freqüência. Nestes registros, não houve diferença estatisticamente significante na latência e na amplitude negativa quando comparado ao grupo controle. Estes achados confirmam a preservação da memória ecóica no grupo de portadores de EM uma vez que 
não diferiram, estatisticamente, das latências e amplitudes negativas obtidas no grupo controle

Santos et al. (2007) realizaram uma pesquisa na qual as alterações observadas no potencial evocado auditivo relacionado a evento no grupo com EM foram as ausências de respostas que ocorreram em $40 \%$ dos indivíduos no protocolo de estimulação auditiva com variação de duração, e em $55 \%$ no protocolo de estimulação auditiva com variação de freqüência.

O Multiple Sclerosis Health Center (2007) enfatizou que, para o diagnóstico de EM, é muito importante também a realização dos PEATE e do P300, visto ter sido comprovado o acometimento da via auditiva do nervo ao tronco encefálico nestes casos, o que pode levar a uma perda auditiva ou a alteração nas latências das ondas do PEATE. O P300 deve ser realizado por se tratar de um exame específico de mensuração das habilidades cognitivas, sendo comum encontrar relatos de pacientes portadores de EM com queixas de déficit de atenção, memória e processamento auditivo. 


\section{Métodos}




\section{4 - MÉTODOS}

Esse estudo foi realizado em Brasília na Clínica Especializada em Fonoaudiologia e Audiologia - Cefau, sendo que a coleta de dados foi realizada na referida clínica

A pequisa recebeu aprovação da Comissão de Ética para Análise de Projetos de Pesquisa - CAPPesq da Diretoria Clínica do Hospital das Clínicas e da Faculdade de Medicina da Universidade de São Paulo, sob protocolo número 0318/07 ( Anexo A).

As avaliações foram realizadas somente após os participantes da pesquisa assinarem o Termo de Consentimento Livre e Esclarecido (Anexo B).

\section{1 - Casuística}

Participaram desta pesquisa 50 indivíduos com idades entre 25 e 55 anos, divididos em dois grupos: 
Grupo Pesquisa (GP): Fizeram parte deste grupo 25 indivíduos com EM do tipo remitente-recorrente ou surto-remissivo, seis do gênero masculino e 19 do gênero feminino, com idades entre 25 e 55 anos (média de 34,88 anos de idade) .

Os indivíduos que compuseram o GP foram encaminhados pela Sociedade de Esclerose Múltipla de Brasília. Foram encaminhadas listas, para a pesquisadora responsável, com os dados dos indivíduos (diagnóstico neurológico, tempo da doença, nome, idade e telefone). Desta forma, a pesquisadora entrou em contato por telefone com os mesmos e agendou a data das avaliações. Muitos sujeitos encaminhados não aceitaram participar da pesquisa por motivos pessoais. Dentre os indivíduos que aceitaram participar, alguns não compareceram na data agendada e outros foram excluídos da pesquisa por apresentarem algum tipo de perda auditiva.

Grupo Controle (GC): Fizeram parte deste grupo 25 indivíduos com histórico de desenvolvimento neurológico normal e sem queixa de zumbido, 19 do gênero feminino e seis do gênero masculino, pareados com GP em idade variando entre 25 e 55 anos (média de 35,16 anos de idade). 
Os indivíduos que compuseram o GC foram selecionados de acordo com idade e sexo e não apresentavam histórico neurológico e queixas audiológicas incluindo o zumbido. A pesquisadora entrou em contato com os mesmos e agendou as datas para as avaliações.

\subsection{1 - Critérios de Inclusão}

Os critérios de inclusão adotados nesta pesquisa foram:

Grupo Pesquisa: faixa etária de 25 a 55 anos com audição normal, diagnóstico médico de EM do tipo remitente recorrente e sem surto num período de seis meses anterior ao início da pesquisa. Os portadores de EM tipo Remitente Recorrente ou Surto Remissivo que aceitaram participar da pesquisa foram encaminhados pela Sociedade de Esclerose Múltipla de Brasília, sendo que estavam diagnosticados e medicados pelo seu neurologista responsável. Vale ressaltar que a faixa etária do grupo pesquisa foi definida de forma aleatória.

Grupo Controle: faixa etária de 25 a 55 anos com audição normal, sem histórico de comprometimento neurológico e sem queixas psiquiátricas, de processamento auditivo e de zumbido. 


\section{2 - Materiais}

Fizeram parte do material deste estudo os resultados das avaliações eletroacústicas e eletrofisiológicas da audição, obtidos nos dois grupos estudados.

Os materiais e equipamentos utilizados para a realização das avaliações serão descritos a seguir:

1 - Questionário elaborado pela pesquisadora responsável baseado no protocolo utilizado pelo Setor de Audiologia Clínica do Curso de Fonoaudiologia da Faculdade de Medicina da Universidade de São Paulo, complementado por um breve histórico clínico dos indivíduos com dados referentes ao inicio da doença (EM), as medicações utilizadas, dados do neurologista que acompanha o paciente e a classificação do tipo da doença. As informações referentes aos medicamentos e classificação da doença foram confirmadas com os neurologistas responsáveis pelos pacientes.

2 - Otoscópio da marca Heine, para a inspeção visual do meato acústico externo;

3 - Analisador de orelha média modelo GSI-33 (ANSI S3.39-1987) da marca Grason-Stadler, para realização das medidas de imitância acústica (avaliação eletroacústica da audição); 
4 - Audiômetro modelo GSI-61 da marca Grason-Stadler e fones de ouvido supra aurais modelo TDH-49 atendendo aos padrões ANSI S3.61989, e cabina acústica atendendo à norma ANSI S3.1-1991 de quantidade de ruído ambiental, ambos para a realização da avaliação audiológica;

5 - Equipamento portátil modelo Masbe Potenciais Evocados Auditivos da Marca - Contronic (ANSI S3.7-1996), com o programa ATCplus2.1 inserido no computador, para a realização da avaliação eletrofisiológica da audição. Este equipamento consiste de um computador portátil, um gerador de estímulos acústicos, um pré-amplificador (caixa na qual são conectados os eletrodos), cinco eletrodos de superfície (cobre), e fones de ouvido supra aurais modelo TDH-39.

\section{3 - Procedimentos}

\subsection{1 - Informações sobre a pesquisa.}

Todos os esclarecimentos referentes à pesquisa, para os pacientes de ambos os grupos, foram realizados na Clínica Especializada em Fonoaudiologia e Audiologia, antes da realização das avaliações. As informações foram passadas, verbalmente, pela pesquisadora seguido do termo de consentimento livre e esclarecido, aprovado previamente pela Comissão de Ética da FMUSP, o qual foi assinado pelo paciente após explicação e leitura. Foi ressaltado aos sujeitos, tanto do grupo controle 
como do grupo pesquisa, que as avaliações a serem realizadas não apresentavam risco algum à saúde do indivíduo, e que os resultados destas avaliações seriam utilizados como dados para pesquisa de Mestrado.

\subsection{2 - Coleta da história clínica.}

Foi realizada uma breve história clínica dos indivíduos para obtenção de dados referentes às queixas auditivas, ao inicio da doença (EM), às medicações utilizadas, dados do neurologista que acompanha o paciente e a classificação do tipo da doença. As informações referentes aos medicamentos e classificação da doença foram confirmadas com cada neurologista.

\subsection{3 - Avaliações eletroacústicas, comportamentais, e} eletrofisiológicas da audição.

Foi realizada a inspeção visual do meato acústico externo, para verificar a existência de possíveis obstruções como cerume ou corpo estranho.

As orientações e avaliações realizadas serão descritas a seguir: 
I - Avaliação Eletroacústica da audição: realizou-se as medidas de imitância acústica (timpanometria e pesquisa dos reflexos acústicos ipsilaterais, nas freqüências de 500,1000, 2000, $4000 \mathrm{~Hz}$ ), sendo que cada indivíduo foi orientado a permanecer quieto, sem se movimentar e/ou falar.

\section{II - Avaliação Audiológica}

II.A - Audiometria Tonal: Testou-se as freqüências de 250, 500, 1000, 2000, 3000, 4000, 6000 e $8000 \mathrm{~Hz}$, sendo que os indivíduos foram orientados a ficar bastante atentos e levantar a mão, ou apertar o "botão", sempre que escutassem o estímulo acústico, mesmo quando estivesse baixo. O exame foi realizado em cabina acústica com fones de ouvido supra-aurais modelo TDH 49.

II.B - Logoaudiometria: Pesquisou-se o Limiar de Reconhecimento de Fala (LRF) e o Índice Percentual de Reconhecimento de Fala (IPRF) com as listas de vocábulos padronizadas por Santos e Russo (1991). Os indivíduos foram orientados a repetir as palavras ditas pela pesquisadora exatamente como entendessem, sendo que os estímulos de fala foram apresentados por meio de fones de ouvido supra-aurais modelo TDH 49 em cabina acústica. 
III - Avaliação Eletrofisiológica da audição: Os PEA foram realizados com o indivíduo sentado em uma cadeira ou deitados em uma maca, dentro de uma sala com tratamento acústico e elétrico. A pele na região da fronte, mastóides e o couro cabeludo foram limpos com pasta abrasiva, sendo fixados os eletrodos com pasta eletrolítica, para melhorar a condutividade elétrica, além de esparadrapo microporoso. Os estímulos acústicos foram apresentados com o fone de ouvido supra-aural modelo TDH 39. A coleta dos PEA foi iniciada pelo P300, seguido do PEAML e, por último, do PEATE.

Esta ordem deve-se ao fato do P300 e do PEAML receberem influências do estado de alerta e atenção ao estímulo acústico, enquanto que o PEATE não recebe este tipo de influência, podendo ser gerado tanto em estado de alerta quanto durante o sono sem modificação de suas respostas. Após a fixação dos eletrodos, realizou-se o teste de impedância dos mesmos que deveria estar abaixo de 5 kOhms, sem haver diferença entre os eletrodos maior que 2 kOhms.

III.A - Potencial Cognitivo (P300): Para a obtenção deste potencial foi utilizado o estímulo acústico tipo "tone-burst", sendo o estímulo freqüente apresentado na frequência de $1000 \mathrm{~Hz}$ e o raro na de $1500 \mathrm{~Hz}$, totalizando 300 estímulos. A apresentação percentual foi de 15\% a 20\% para o estímulo raro, sendo o restante para o estímulo freqüente. O estímulo acústico foi apresentado monoauralmente a $75 \mathrm{~dB}$ NA, com uma velocidade de apresentação de 1,1 estimulos por segundo. Os eletrodos foram fixados no 
vértex (Cz) e nas mastóides direita e esquerda (A2 e A1). Neste potencial foi necessário apenas a gravação de um registro para cada lado, não havendo a necessidade de reprodução das ondas.

Os indivíduos foram orientados para manter sua atenção no estímulo raro que surgia aleatoriamente dentro de uma série de estímulos freqüentes durante o exame. Foi solicitado a contagem, em voz alta, do número de vezes que o paciente escutasse o estímulo raro. (Durrant e Ferraro, 2001; Musiek e Lee, 2001).

\section{III.B - Potencial Evocado Auditivo de Média Latência (PEAML)}

Este potencial foi realizado com estímulo acústico do tipo clique, apresentado monoauralmente a $70 \mathrm{~dB}$ NA, com velocidade de apresentação de 9,9 estímulos por segundo, totalizando 1000 estímulos. Os eletrodos foram posicionados no vértex $(\mathrm{Cz})$, nas mastóides direita e esquerda (A2 e A1), e junções têmporo-parietais direita e esquerda (C4 e C3). Para este potencial houve a necessidade de dois registros para cada modalidade (ipsi e contralateral - C3/A1, C4/A2, C3/A2, e C4/A1), possibilitando assim a realização dos cálculos necessários para a análise do mesmo. Os indivíduos foram orientados a ficarem quietos, sem realizarem movimentos com a região da cabeça e pescoço que pudessem prejudicar a obtenção das respostas, e a ficarem atentos ao som sem dormir e falar. 


\section{III.C - Potencial Evocado Auditivo de Tronco Encefálico} (PEATE): Neste exame foram apresentados monoauralmente 2000 estimulos do tipo clique com polaridade rarefeita, na intensidade de $80 \mathrm{~dB}$ NA, em uma velocidade de apresentação de 19,9 cliques por segundo. Os eletrodos foram fixados no vértex $(\mathrm{Cz})$ e nas mastóides direita e esquerda (A2 e A1). Para coleta deste potencial houve a necessidade de dois registros para cada lado, verificando a existência de reprodutibilidade dos traçados e confirmando, assim, a presença de respostas. Os indivíduos foram orientados a ficarem quietos, sem realizarem movimentos com a região da cabeça e pescoço que pudessem prejudicar a obtenção das respostas, e a ficarem sem falar.

O tempo médio necessário para a realização da série de exames com cada indivíduo foi de aproximadamente uma hora e trinta minutos, tanto para o GC como para o grupo GP, possibilitando assim a realização das avaliações em um único dia.

\section{4 - Critérios de avaliação dos resultados}

Os resultados das avaliações audiológicas, eletroacústicas e eletrofisiológicas da audição foram classificados em normal e alterado, para cada indivíduo. As alterações encontradas em cada exame serão descritas posteriormente. 
Os resultados foram considerados normais desde que seguissem os seguintes padrões:

I - Medidas de Imitância Acústica: presença de curva timpanométrica tipo A (Jerger, 1970), e reflexos acústicos ipsilaterais presentes nas freqüências de 500, 1000, e $2000 \mathrm{~Hz}$, entre as intensidades de 80 e 95 dB NA (Carvallo et al., 2000).

II - Audiometria Tonal: limiares auditivos menores ou iguais a $20 \mathrm{~dB}$ NA nas freqüências de 500, 1000, 2000 e 4000 Hz (BIAP,2003 ).

\section{III - Logoaudiometria:}

- LRF com resultados iguais ou até $10 \mathrm{~dB}$ acima da média dos limiares auditivos nas freqüências de 500, 1000, e $2000 \mathrm{~Hz}$ na audiometria tonal por via aérea (Santos e Russo, 1991).

- IPRF com percentagem de acerto entre $88 \%$ e $100 \%$ (Gates e Chakeres, 1988) numa intensidade de 30dB NA acima do valor encontrado no LRF. 
IV - PEATE: foi realizada análise dos valores de latências absolutas das ondas I, III, e V, e interpicos I-III, III-V, e I-V. O padrão de normalidade utilizado foram os valores propostos pelo manual do usuario do ATCplus do equipamento Masbe, para crianças acima de 24 meses, que se encontram no quadro 1.

Quadro 1: Padrão de normalidade dos valores de latências e interpicos do PEATE, para indivíduos acima de 24 meses, proposto pelo manual do usuário do ATCplus

\begin{tabular}{|c|c|c|c|c|c|c|}
\hline & Onda I & Onda III & Onda V & $\begin{array}{c}\text { Interpico } \\
\text { I-III }\end{array}$ & $\begin{array}{c}\text { Interpico } \\
\text { III-V }\end{array}$ & $\begin{array}{c}\text { Interpico } \\
\text { I-V }\end{array}$ \\
\hline $\begin{array}{c}\text { Média } \\
\text { (ms) }\end{array}$ & 1,48 & 3,55 & 5,43 & 2,15 & 1,82 & 4,00 \\
\hline $\begin{array}{c}\text { Desvio } \\
\text { Padrão } \\
\text { (ms) }\end{array}$ & 0,15 & 0,19 & 0,25 & 0,22 & 0,15 & 0,23 \\
\hline
\end{tabular}

V - PEAML: foi realizada a análise dos valores obtidos na amplitude (Na-Pa) da onda $\mathrm{Pa}$, nas quatro modalidades estudadas. Utilizou-se a análise proposta por Musiek e Lee (2001), na qual a diferença menor ou igual a 50\% entre as amplitudes obtidas, na comparação das modalidades ipsilateral e contralateral (C3/A1, C4/A2, C3/A2, C4/A1), duas a duas, indica normalidade. 
Os valores referentes às latências das ondas $\mathrm{Na}$ e $\mathrm{Pa}$ também foram considerados na análise dos resultados, apresentando o seguinte padrão de normalidade:

Quadro 2: Padrão de normalidade dos valores de latências das ondas Na e Pa do PEAML, proposto por McGee et al. (2001)

\begin{tabular}{|l|c|c|}
\cline { 2 - 3 } \multicolumn{1}{c|}{} & Onda Na & Onda Pa \\
\hline $\begin{array}{l}\text { Média } \\
\text { (ms) }\end{array}$ & 17,91 & 29,41 \\
\hline $\begin{array}{l}\text { Desvio } \\
\text { Padrão } \\
\text { (ms) }\end{array}$ & 2,60 & 5,66 \\
\hline
\end{tabular}

VI - P300: para a análise deste potencial, considerou-se o valor de latência obtido para a onda P300. Os valores de normalidade utlizados foram os propostos por McPherson (1996), para cada faixa etária, conforme o quadro 3.

Quadro 3: Padrão de normalidade dos valores de latência da onda P300, para cada faixa etária, proposto por McPherson (1996)

\begin{tabular}{|c|c|}
\hline Faixa etária & Latência da onda P300 \\
\hline 17 a 30 anos & 225 a 365 milissegundos \\
\hline 30 a 50 anos & 290 a 380 milissegundos \\
\hline 50 a 70 anos & 350 a 427 milissegundos \\
\hline
\end{tabular}


Os resultados que não estivessem de acordo com os critérios supracitados foram considerados alterados, sendo que o indivíduo foi classificado como tendo resultado alterado quando pelo menos um dos lados ou uma das orelhas não estavam em conformidade com a normalidade.

Os indivíduos que apresentaram alteração nas medidas de imitância acústica, audiometria tonal e logoaudiometria foram excluídos da amostra e não participaram da pesquisa.

Os resultados que não se encontraram de acordo com os critérios previamente descritos foram considerados alterados. O indivíduo foi considerado alterado quando pelo menos uma das orelhas, ou um dos lados, apresentava alteração. Os tipos de alterações encontradas foram classificadas para cada potencial realizado.

As alterações encontradas nos PEA foram classificadas de acordo com cada exame realizado:

I - PEATE: Os resultados obtidos e considerados alterados foram divididos de acordo com a localização da alteração: 
- Tronco Encefálico Baixo (TEB): quando as latências das ondas III e $\mathrm{V}$ e os interpicos I-III e I-V apresentavam-se aumentados, com latências normais para a onda I e interpico III-V, o resultado foi considerado como sugestivo de alteração da via auditiva em tronco encefálico baixo.

- Tronco Encefálico Alto (TEA): quando a latência da onda $V$ e os interpicos I-V e III-V encontravam-se aumentados, com latências absolutas normais para as ondas I e III e interpico I-III, o resultado foi considerado como sugestivo de alteração da via auditiva em tronco encefálico alto.

- Ambas: quando encontradas alterações do tipo TEB e TEA, para o mesmo indivíduo.

II - PEAML: Foi utilizada a classificação proposta por Musiek e Lee (2001), sendo indicativo de disfunção quando ocorreu uma diferença maior que 50\% entre as amplitudes obtidas na comparação das modalidades ipsilateral e contralateral (C3/A1, C4/A2, C3/A2, C4/A1), duas a duas. Estas disfunções foram classificadas em Efeito Eletrodo (EE) e Efeito Orelha (EO), a saber:

- Efeito Eletrodo (EE): quando ocorreu uma diferença maior que 50\%, comparadas nas medidas de amplitude da onda $\mathrm{Pa}$ com os eletrodos posicionados sobre cada junção têmporo-parietal (comparação entre C3/A1 e C4/A1; e entre C3/A2 e C4/A2). 
- Efeito Orelha (EO): quando uma orelha, independente do local do eletrodo (comparação entre C3/A1 e C3/A2; e entre C4/A1 e C4/A2), apresentou amplitudes da onda Pa reduzidas de forma constante.

- Ambas: quando encontradas alterações do tipo EE e EO para o mesmo indivíduo.

As latências das ondas $\mathrm{Na}$ e Pa estiveram alteradas quando os valores obtidos excediam a normalidade referida, sendo esta alteração classificada como atraso de latência.

III - P300: Os resultados considerados alterados foram divididos em:

- Atraso de latência: quando a latência da onda P300 encontrava-se aumentada, se comparada aos valores de normalidade.

- Ausência de resposta: quando não foi encontrada a onda P300.

- Ambas: quando foram encontradas alterações do tipo atraso de latência e ausência de resposta para o mesmo indivíduo.

\section{5 - Método estatístico}

No presente trabalho realizamos a análise qualitativa possibilitando assim a comparação dos resultados normais e alterados encontrados nos PEA em cada grupo e entre os grupos. 
Para a análise das variáveis qualitativas os seguintes testes foram aplicados:

- Teste Exato de Fisher, um teste paramétrico, o qual compara se a proporção de respostas de duas determinadas variáveis, e/ou seus níveis, é estatisticamente significante;

- Intervalo de Confiança para Proporção, técnica utilizada visando verificar o quanto a proporção pode variar numa determinada probabilidade de confiança.

Este trabalho foi submetido, também, a uma análise quantitativa na qual foi verificado média, mediana, desvio padrão, limite inferior, limite superior, máximo e mínimo dos resultados para cada PEA, nos dois grupos. Além disso, foram comparadas as médias entre os grupos e verificados os níveis de significância para cada comparação. Para a análise das variáveis quantitativas, utilizamos os testes:

- Teste normativo de Anderson-Darling - um teste paramétrico bastante usual que compara as médias, utilizando a variância aplicado no software Minitab; 
- INTervalo de Confiança para a Média - uma técnica utilizada para verificar o quanto a média pode variar numa determinada probabilidade de confiança.

As comparações realizadas possuem um dado estatístico chamado de p-valor. Neste trabalho foi utilizado um nível de significância de 0,05 (5\%) para este valor e os resultados que apresentaram diferença estatisticamente significante foram assinalados com asterisco $\left({ }^{*}\right)$. Vale ressaltar que todos os intervalos de confiança do trabalho foram construídos com 95\% de confiança estatística. 


\section{Resultados}




\section{5 - RESULTADOS}

A seguir descreveremos os resultados obtidos nos potenciais evocados auditivos de 50 sujeitos, sendo 25 do Grupo Pesquisa (GP) e 25 do Grupo Controle (GC).

Dividiremos este capítulo em três partes, uma para cada tipo de potencial evocado auditivo (PEATE, PEAML, e P300), com o intuito de facilitar a apresentação e visualização dos resultados.

Caracterização dos resultados das avaliações eletrofisiológicas nos grupos controle e pesquisa.

Serão apresentadas as análises qualitativas e quantitativas dos resultados obtidos nas avaliações eletrofisiológicas da audição, para os dois grupos.

$\mathrm{Na}$ análise qualitativa, os resultados foram classificados em normais e alterados, e em tipos de alterações, seguindo os critérios apresentados no capítulo de Método. 
$\mathrm{Na}$ análise quantitativa, foram estabelecidos os valores de média, mediana, desvio padrão, limite inferior, limite superior, máximo e mínimo dos resultados de cada PEA, para cada grupo. Além disso, comparou-se os valores de média obtidos entre os grupos, verificando os níveis de significância em cada comparação realizada.

Parte I - Resultados do Potencial Evocado Auditivo de Tronco Encefálico nos grupos controle e pesquisa.

Parte II - Resultados do Potencial Evocado Auditivo de Média Latência nos grupos controle e pesquisa.

Parte III - Resultados do Potencial Cognitivo nos grupos controle e pesquisa.

\section{Parte I - Resultados do Potencial Evocado Auditivo de Tronco Encefálico nos grupos controle e pesquisa.}

Inicialmente realizou-se a comparação entre as orelhas direita e esquerda para as latências absolutas das ondas I, III e V e os interpicos I-III, III-V e I-V do PEATE, nos grupos controle e pesquisa. Para realizar tal comparação foi utilizado o TESTE NORMATIVO DE ANDERSON-DARLING. 
TABELA 1 - Comparação dos valores médios das latências absolutas das ondas I, III e V e dos interpicos I-III, III-V, e I-V em ms entre as orelhas direita e esquerda no PEATE, para o grupo controle

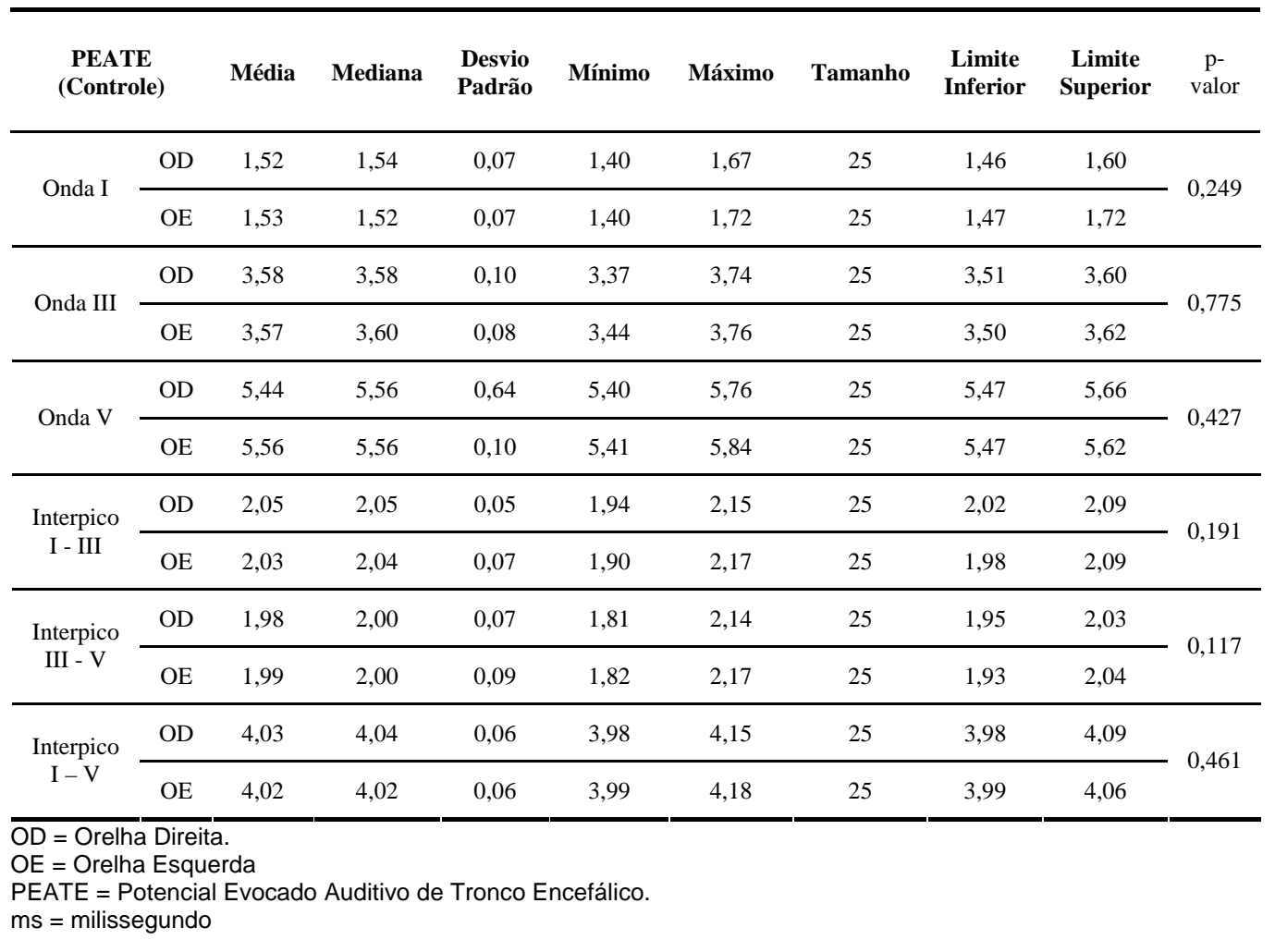

$\mathrm{Na}$ tabela 1 pode-se verificar que não ocorreu diferença estatisticamente significante entre as orelhas direita e esquerda para as latências absolutas das ondas I, III e V, e interpicos I-III, III-V e I-V do PEATE, no grupo controle. 
TABELA 2 - Comparação dos valores médios das latências absolutas das ondas I, III, e V e dos interpicos I-III, III-V, e I-V em ms entre as orelhas direita e esquerda no PEATE, para o grupo pesquisa

\begin{tabular}{|c|c|c|c|c|c|c|c|c|c|c|}
\hline \multicolumn{2}{|c|}{$\begin{array}{c}\text { PEATE } \\
\text { (Pesquisa) }\end{array}$} & Média & Mediana & $\begin{array}{l}\text { Desvio } \\
\text { Padrão }\end{array}$ & Mínimo & Máximo & Tamanho & $\begin{array}{c}\text { Limite } \\
\text { Inferior }\end{array}$ & $\begin{array}{c}\text { Limite } \\
\text { Superior }\end{array}$ & p-valor \\
\hline \multirow{2}{*}{ Onda I } & OD & 1,53 & 1,52 & 0,14 & 1,40 & 1,62 & 25 & 1,40 & 1,62 & \multirow{2}{*}{0,489} \\
\hline & $\mathrm{OE}$ & 1,53 & 1,55 & 0,12 & 1,45 & 1,62 & 25 & 1,45 & 1,62 & \\
\hline \multirow{2}{*}{ Onda III } & OD & 3,74 & 3,74 & 0,37 & 3,62 & 4,88 & 25 & 3,55 & 3,97 & \multirow{2}{*}{0,307} \\
\hline & $\mathrm{OE}$ & 3,69 & 3,64 & 0,24 & 3,31 & 4,37 & 25 & 3,50 & 3,87 & \\
\hline \multirow{2}{*}{ Onda V } & OD & 5,81 & 5,74 & 0,45 & 5,36 & 7,2 & 25 & 5,48 & 5,97 & \multirow{2}{*}{0,281} \\
\hline & $\mathrm{OE}$ & 5,75 & 5,71 & 0,27 & 5,36 & 6,37 & 25 & 5,54 & 5,97 & \\
\hline \multirow{2}{*}{$\begin{array}{c}\text { Interpico } \\
\text { I - III }\end{array}$} & OD & 2,25 & 2,24 & 0,30 & 1,81 & 3,38 & 25 & 2,09 & 2,37 & \multirow{2}{*}{0,858} \\
\hline & $\mathrm{OE}$ & 2,16 & 2,19 & 0,20 & 1,81 & 2,52 & 25 & 2,02 & 2,33 & \\
\hline \multirow{2}{*}{$\begin{array}{l}\text { Interpico } \\
\text { III - V }\end{array}$} & OD & 2,02 & 1,99 & 0,29 & 1,66 & 2,98 & 25 & 1,80 & 2,16 & \multirow{2}{*}{0,307} \\
\hline & $\mathrm{OE}$ & 2,04 & 2,01 & 0,26 & 1,64 & 2,72 & 25 & 1,85 & 2,21 & \\
\hline \multirow{2}{*}{$\begin{array}{l}\text { Interpico } \\
\mathrm{I}-\mathrm{V}\end{array}$} & OD & 4,27 & 4,21 & 0,42 & 3,83 & 5,47 & 25 & 3,94 & 4,39 & \multirow{2}{*}{0,421} \\
\hline & $\mathrm{OE}$ & 4,21 & 4,21 & 0,26 & 3,79 & 4,75 & 25 & 4,00 & 4,44 & \\
\hline
\end{tabular}

Para a grupo pesquisa, como evidenciado na Tabela 2, também não foram observadas diferenças estatisticamente significantes para as latências absolutas das ondas I, III e V, e interpicos I-III, III-V e I-V do PEATE, entre as orelhas direita e esquerda.

Como não ocorreram diferenças médias estatisticamente significantes entre as orelhas direita e esquerda, nos grupos controle e pesquisa, para as variáveis estudadas (latências absolutas e interpicos), os valores obtidos nas orelhas direita e esquerda foram agrupados. Desta forma, as próximas análises foram realizadas considerando um total de 50 orelhas. 
Ainda considerando-se a análise dos dados quantitativos, foram comparadas a seguir as latências absolutas das ondas I, III e V, e os interpicos I-III, III-V e I-V entre os grupos controle e pesquisa.

TABELA 3 - Comparação dos valores médios das latências absolutas das ondas I, III e V e dos interpicos I-III, III-V, e I-V em ms, entre os grupos controle e pesquisa

\begin{tabular}{|c|c|c|c|c|c|c|c|c|c|c|}
\hline \multicolumn{2}{|c|}{$\begin{array}{c}\text { PEATE } \\
\text { (Pesquisa) }\end{array}$} & Média & Mediana & $\begin{array}{l}\text { Desvio } \\
\text { Padrão }\end{array}$ & Mínimo & Máximo & Tamanho & $\begin{array}{c}\text { Limite } \\
\text { Inferior }\end{array}$ & $\begin{array}{l}\text { Limite } \\
\text { Superior }\end{array}$ & p-valor \\
\hline \multirow{2}{*}{ Onda I } & GC & 1,53 & 1,53 & 0,07 & 1,40 & 1,72 & 50 & 1,47 & 1,60 & \multirow{2}{*}{0,754} \\
\hline & GP & 1,53 & 1,55 & 0,13 & 1,27 & 1,85 & 50 & 1,44 & 1,62 & \\
\hline \multirow{2}{*}{ Onda III } & GC & 3,57 & 3,59 & 0,09 & 3,37 & 3,76 & 50 & 3,51 & 3,62 & \multirow{2}{*}{$0,003^{*}$} \\
\hline & GP & 3,72 & 3,70 & 0,31 & 3,28 & 4,88 & 50 & 3,52 & 3,87 & \\
\hline \multirow{2}{*}{ Onda V } & GC & 5,50 & 5,56 & 0,45 & 5,40 & 5,84 & 50 & 5,47 & 5,84 & \multirow{2}{*}{$0,005^{*}$} \\
\hline & GP & 5,78 & 5,51 & 0,37 & 5,36 & 7,2 & 50 & 5,51 & 5,95 & \\
\hline \multirow{2}{*}{$\begin{array}{l}\text { Interpico } \\
\text { I - III }\end{array}$} & GC & 2,04 & 2,04 & 0,06 & 1,90 & 2,17 & 50 & 2,0 & 2,09 & \multirow{2}{*}{$0,005^{*}$} \\
\hline & GP & 2,21 & 2,20 & 0,26 & 1,81 & 3,38 & 50 & 2,06 & 2,37 & \\
\hline \multirow{2}{*}{$\begin{array}{l}\text { Interpico } \\
\text { III - V }\end{array}$} & GC & 1,98 & 2,00 & 0,08 & 1,81 & 2,17 & 50 & 1,94 & 2,04 & \multirow{2}{*}{0,264} \\
\hline & GP & 2,03 & 1,99 & 0,27 & 1,64 & 2,98 & 50 & 1,84 & 2,17 & \\
\hline \multirow{2}{*}{$\begin{array}{c}\text { Interpico } \\
\text { I - V }\end{array}$} & GC & 4,03 & 4,02 & 0,06 & 3,91 & 4,18 & 50 & 3,98 & 4,07 & \multirow{2}{*}{$0,005^{*}$} \\
\hline & GP & 4,26 & 4,21 & 0,35 & 3,79 & 5,47 & 50 & 3,98 & 4,41 & \\
\hline
\end{tabular}

* p-valor considerado estatisticamente significante perante o nível de significância adotado.

$\mathrm{GC}=$ Grupo Controle

GP = Grupo Pesquisa

PEATE = Potencial Evocado Auditivo de Tronco Encefálico

$\mathrm{ms}=$ milissegundos

Na Tabela 3 pode-se observar diferenças estatisticamente significantes entre os grupos controle e pesquisa para as latências absolutas das ondas III e V e os interpicos I-III e I-V. 
A seguir foi realizada a análise dos dados qualitativos, comparando-se os resultados normais e alterados obtidos no PEATE, para cada grupo avaliado e entre os grupos (Tabela 4).

TABELA 4 - Distribuição da ocorrência de resultados normais e alterados no PEATE, nos grupos controle e pesquisa

\begin{tabular}{|c|c|c|c|c|c|c|c|}
\hline \multirow{2}{*}{ PEATE } & \multicolumn{3}{|c|}{ Grupo Controle } & \multicolumn{3}{|c|}{ Grupo Pesquisa } & \multirow{2}{*}{ p-valor } \\
\hline & $\mathbf{N}$ & $\%$ & Var & $\mathbf{N}$ & $\%$ & Var & \\
\hline Normal & 25 & $100,0 \%$ & \multirow{2}{*}{$0,0 \%$} & 08 & $32, \%$ & \multirow{2}{*}{$23,7 \%$} & \multirow{2}{*}{$<0,001^{*}$} \\
\hline Alterado & 0 & $0,0 \%$ & & 17 & $68 \%$ & & \\
\hline p-valor & & $<0,001^{*}$ & & & 0,157 & & \\
\hline
\end{tabular}

* p-valor considerado estatisticamente significante perante o nível de significância adotado. $\mathrm{N}=$ número de indivíduos

Var = índice de variação em relação à média

Pode-se observar na tabela 4 que ocorreu diferença estatisticamente significante entre os resultados normal e alterado no grupo controle, sendo que esta diferença não foi considerada estatisticamente significante para o grupo pesquisa. Na comparação entre os grupos controle e pesquisa, verificou-se também diferença estatisticamente significante para os resultados normal e alterado.

$\mathrm{Na}$ Tabela 5 foram comparadas as alterações encontradas no PEATE entre os grupos controle e pesquisa, e em um mesmo grupo. 
TABELA 5 - Distribuição dos tipos de alterações encontradas no PEATE, nos grupos controle e pesquisa

\begin{tabular}{ccccc}
\hline Alterações & & Controle & Pesquisa & p-valor \\
\hline \multirow{2}{*}{$\begin{array}{c}\text { Tronco encefálico } \\
\text { baixo }\end{array}$} & $\mathrm{N}$ & 0 & 7 & \\
\cline { 2 - 4 } & $\%$ & $0,0 \%$ & $41 \%$ & - \\
\hline \multirow{2}{*}{ Tronco encefálico alto } & $\mathrm{N}$ & 0 & 5 & \multirow{2}{*}{ - - } \\
\cline { 2 - 4 } & $\%$ & $0,0 \%$ & $29,5 \%$ & \\
\hline \multirow{2}{*}{ Ambas } & $\mathrm{N}$ & 0 & 5 & - \\
\cline { 2 - 4 } & $\%$ & $0,0 \%$ & $29,5 \%$ & \\
\hline
\end{tabular}

\begin{tabular}{cccc}
\hline & Alterações & $\begin{array}{c}\text { Tronco encefálico } \\
\text { baixo }\end{array}$ & $\begin{array}{c}\text { Tronco encefálico } \\
\text { alto }\end{array}$ \\
\hline \multirow{2}{*}{ Controle } & $\begin{array}{c}\text { Tronco encefálico } \\
\text { alto }\end{array}$ & -- & -- \\
\cline { 2 - 4 } & Ambas & -- & -- \\
\hline \multirow{2}{*}{ Pesquisa } & $\begin{array}{c}\text { Tronco encefálico } \\
\text { alto }\end{array}$ & $0,004^{*}$ & -- \\
\cline { 2 - 4 } & Ambas & $0,004^{*}$ & 0,258 \\
\hline
\end{tabular}

* $\mathrm{p}$-valor considerado estatisticamente significante

$\mathrm{N}=$ número de indivíduos

Var = índice de variação em relação a média

Devido ao fato do grupo controle não ter apresentado resultados alterados, não houve possibilidade de realizar a comparação dos tipos de alterações entre os grupos.

Verificou-se que a alteração de tronco encefálico baixo foi a mais freqüente no grupo pesquisa (41\%), sendo considerada estatisticamente significante em relação aos demais tipos de alterações (tronco encefálico alto e ambas). 


\section{Parte II - Resultados do Potencial Evocado Auditivo de Média}

\section{Latência nos grupos controle e pesquisa.}

Iniciou-se a análise do PEAML comparando as orelhas direita e esquerda em cada grupo estudado. Foram comparados os valores de latência das ondas $\mathrm{Na}$ e $\mathrm{Pa}$, entre as modalidades C3/A1 e C3/A2, e as modalidades C4/A1 e C4/A2, nos grupos controle e pesquisa.

TABELA 6 - Comparação dos valores médios das latências da onda Na em ms, entre as modalidades C3/A1 e C3/A2, e entre C4/A1 e C4/A2 do PEAML, no grupo controle

\begin{tabular}{lcccc}
\hline \multirow{2}{*}{$\begin{array}{c}\text { PEAML (Controle) } \\
\text { Latência da Onda Na em } \\
\text { ms }\end{array}$} & $\mathbf{A}$ & $\mathbf{A 2}$ & $\mathbf{A 1}$ & $\mathbf{A 2}$ \\
\cline { 2 - 6 } Média & 18,13 & 18,53 & 18,09 & 17,52 \\
\hline Mediana & 17,43 & 17,19 & 17,76 & 16,99 \\
\hline Desvio Padrão & 2,6 & 2,4 & 2,77 & 2,05 \\
\hline Mínimo & 14,06 & 16,01 & 11,90 & 14,04 \\
\hline Máximo & 25,82 & 25,82 & 25,82 & 21,53 \\
\hline Tamanho & 25 & 25 & 25 & 25 \\
\hline Limite Inferior & 16,5 & 17,19 & 16,16 & 16,47 \\
\hline Limite Superior & 19,04 & 25,82 & 19,81 & 18,81 \\
\hline p-valor & \multicolumn{3}{c}{0,180} & \multicolumn{2}{c}{0,351} \\
\hline
\end{tabular}

C3 = junção têmporo-parietal esquerda

C4 = junção têmporo-parietal direita

$\mathrm{A} 1$ = mastóide esquerda

A2 = mastóide direita

$\mathrm{ms}=$ milissegundos

PEAML = Potencial Evocado Auditivo de Média Latência 
TABELA 7 - Comparação dos valores médios das latências da onda $\mathrm{Pa}$ em ms, entre as modalidades C3/A1 e C3/A2, e entre C4/A1 e C4/A2 do PEAML, no grupo controle

\begin{tabular}{lcccc}
\hline \multirow{2}{*}{$\begin{array}{c}\text { PEAML (Controle) } \\
\text { Latência da Onda Pa em } \\
\text { ms }\end{array}$} & A1 & A2 & A1 & A2 \\
\cline { 2 - 6 } Média & 31,95 & 30,90 & 31,09 & 30,31 \\
\hline Mediana & 31,90 & 30,34 & 32,02 & 30,71 \\
\hline Desvio Padrão & 2,34 & 3,31 & 4,04 & 3,21 \\
\hline Mínimo & 28,41 & 23,80 & 15,81 & 18,71 \\
\hline Máximo & 36,41 & 35,99 & 35,47 & 31,73 \\
\hline Tamanho & 25 & 25 & 25 & 25 \\
\hline Limite Inferior & 29,74 & 28,68 & 29,50 & 29,98 \\
\hline Limite Superior & 34,16 & 34,05 & 33,85 & 31,73 \\
\hline p-valor & \multicolumn{3}{c}{0,264} \\
\hline
\end{tabular}

C3 = junção têmporo-parietal esquerda

C4 = junção têmporo-parietal direita

A1 = mastóide esquerda

A2 = mastóide direito

$\mathrm{ms}=$ milissegundos

PEAML = Potencial Evocado Auditivo de Média Latência

Nas tabelas 6 e 7 não evidenciou-se diferença estatisticamente significante para as latências das ondas $\mathrm{Na}$ e $\mathrm{Pa}$ entre as modalidades C3/A1 e C3/A2, e entre C4/A1 e C4/A2, no grupo controle. 
TABELA 8 - Comparação dos valores médios das latências da onda $\mathrm{Na}$ em ms, entre as modalidades C3/A1 e C3/A2, e entre C4/A1 e C4/A2 do PEAML, no grupo pesquisa

\begin{tabular}{lcccc}
\hline \multirow{2}{*}{$\begin{array}{c}\text { PEAML (Pesquisa) } \\
\text { Latência da Onda Na em } \\
\text { ms }\end{array}$} & $\mathbf{A 1}$ & $\mathbf{A 2}$ & $\mathbf{A 1}$ & $\mathbf{A 2}$ \\
\cline { 2 - 6 } Média & 21,84 & 21,92 & 22,35 & 22,57 \\
\hline Mediana & 20,86 & 21,36 & 21,02 & 17,72 \\
\hline Desvio Padrão & 4,2 & 5,2 & 4,8 & 5,3 \\
\hline Mínimo & 16,06 & 15,31 & 15,94 & 14,93 \\
\hline Máximo & 29,18 & 32,12 & 31,70 & 31,58 \\
\hline Tamanho & 25 & 25 & 25 & 25 \\
\hline Limite Inferior & 17,97 & 17,02 & 18,41 & 17,72 \\
\hline Limite Superior & 26,28 & 26,72 & 26,55 & 27,66 \\
\hline p-valor & \multicolumn{3}{c}{0,204} & \multicolumn{2}{c}{0,416} \\
\hline
\end{tabular}

C3 = junção têmporo-parietal esquerda

C4 = junção têmporo-parietal direita

A1 = mastóide esquerda

A2 = mastóide direita

$\mathrm{ms}=$ milissegundos

PEAML = Potencial Evocado Auditivo de Média Latência 
TABELA 9 - Comparação dos valores médios das latências da onda Pa em ms, entre as modalidades C3/A1 e C3/A2, e entre C4/A1 e C4/A2 do PEAML, no grupo pesquisa

\begin{tabular}{lcccc}
\hline \multirow{2}{*}{$\begin{array}{c}\text { PEAML (Pesquisa) } \\
\text { Latência da Onda Pa em } \\
\text { ms }\end{array}$} & $\mathbf{A}$ & A2 & A1 & A2 \\
\cline { 2 - 6 } Média & 28,53 & 28,42 & 27,56 & 28,58 \\
\hline Mediana & 29,43 & 29,34 & 27,79 & 24,03 \\
\hline Desvio Padrão & 4,5 & 4,8 & 4,3 & 4,7 \\
\hline Mínimo & 18,21 & 19,22 & 19,59 & 19,59 \\
\hline Máximo & 36,12 & 32,08 & 36,37 & 36,37 \\
\hline Tamanho & 25 & 25 & 25 & 25 \\
\hline Limite Inferior & 24,47 & 24,20 & 23,82 & 24,03 \\
\hline Limite Superior & 31,91 & 32,08 & 30,77 & 32,04 \\
\hline p-valor & \multicolumn{3}{c}{0,910} & \multicolumn{2}{c}{0,344} \\
\hline
\end{tabular}

C3 = junção têmporo-parietal esquerda

C4 = junção têmporo-parietal direita

A1 = mastóide esquerda

A2 = mastóide direita

$\mathrm{ms}=$ milissegundos

PEAML = Potencial Evocado Auditivo de Média Latência

Nas tabelas 8 e 9 não evidenciou-se diferença estatisticamente significante para as latências das ondas $\mathrm{Na}$ e $\mathrm{Pa}$ entre as modalidades C3/A1 e C3/A2, e entre C4/A1 e C4/A2, no grupo pesquisa.

Foram comparados, também, os valores de amplitude $\mathrm{Na}$ - $\mathrm{Pa}$, entre as modalidades C3/A1 e C3/A2, e as modalidades C4/A1 e C4/A2, nos grupos controle e pesquisa. 
TABELA 10 - Comparação dos valores médios das amplitudes Na-Pa em $\mu \mathrm{v}$ entre as modalidades C3/A1 e C3/A2, e entre C4/A1 e C4/A2 do PEAML, no grupo controle

\begin{tabular}{lcccc}
\hline \multirow{2}{*}{$\begin{array}{c}\text { PEAML (Controle) } \\
\text { Amplitude Na-Pa em } \mathbf{~ p v}\end{array}$} & $\mathbf{c}$ C3 & A2 & A1 & A2 \\
\cline { 2 - 5 } & 1,32 & 1,21 & 1,21 & 1,58 \\
\hline Média & 1,26 & 1,27 & 1,21 & 1,43 \\
\hline Mediana & 0,54 & 0,46 & 0,50 & 0,68 \\
\hline Desvio Padrão & 0,49 & 0,47 & 0,40 & 0,49 \\
\hline Mínimo & 2,18 & 2,13 & 2,12 & 3,12 \\
\hline Máximo & 25 & 25 & 25 & 25 \\
\hline Tamanho & 0,85 & 0,83 & 0,72 & 0,85 \\
\hline Limite Inferior & 1,83 & 1,44 & 1,64 & 1,84 \\
\hline Limite Superior & \multicolumn{3}{c}{0,280} & \multicolumn{2}{c}{0,178} \\
\hline p-valor & \multicolumn{5}{c}{ C4 } \\
\hline
\end{tabular}

C3 = junção têmporo-parietal esquerda

C4 = junção têmporo-parietal direita

A1 = mastóide esquerda

A2 = mastóide direita

$\mu \mathrm{v}=$ microvolts

PEAML = Potencial Evocado Auditivo de Média Latência

No grupo controle, conforme observado na Tabela 10, não foi encontrada diferença estatisticamente significante para as amplitudes $\mathrm{Na}-\mathrm{Pa}$ entre as modalidades C3/A1 e C3/A2, e entre C4/A1 e C4/A2 do PEAML. 
TABELA 11 - Comparação dos valores médios das amplitudes Na-Pa em $\mu \mathrm{v}$ entre as modalidades C3/A1 e C3/A2, e entre C4/A1 e C4/A2 do PEAML, no grupo pesquisa

\begin{tabular}{lcccc}
\hline \multirow{2}{*}{$\begin{array}{c}\text { PEAML (Pesquisa) } \\
\text { Amplitude Na-Pa em } \mathbf{\mu v}\end{array}$} & $\mathbf{c}$ C3 & A2 & A1 & A2 \\
\cline { 2 - 5 } & 1,51 & 1,41 & 1,21 & 1,58 \\
\hline Média & 1,17 & 1,05 & 1,0 & 1,43 \\
\hline Mediana & 0,83 & 0,93 & 0,72 & 0,71 \\
\hline Desvio Padrão & 0,51 & 0,32 & 0,27 & 0,43 \\
\hline Mínimo & 3,51 & 4,04 & 2,91 & 3,10 \\
\hline Máximo & 25 & 25 & 25 & 25 \\
\hline Tamanho & 0,84 & 0,76 & 0,71 & 1,05 \\
\hline Limite Inferior & 3,51 & 4,04 & 2,91 & 3,10 \\
\hline Limite Superior & \multicolumn{3}{c}{0,223} \\
\hline p-valor & \multicolumn{5}{c}{0,269} \\
\hline
\end{tabular}

C3 = junção têmporo-parietal esquerda

C4 = junção têmporo-parietal direita

A1 = mastóide esquerda

A2 = mastóide direita

$\mu v=$ microvilts

PEAML = Potencial Evocado Auditivo de Média Latência

Para o grupo pesquisa, conforme descrito na Tabela 11, não ocorreu diferença estatisticamente significante nas amplitudes $\mathrm{Na}-\mathrm{Pa}$ entre as modalidades C3/A1 e C3/A2 e entre C4/A1 e C4/A2 do PEAML.

A comparação das amplitudes $\mathrm{Na}-\mathrm{Pa}$ entre as modalidades C3/A1 e C4/A1, e entre C3/A2 e C4/A2 também foi realizada para cada grupo estudado. 
TABELA 12 - Comparação dos valores médios das amplitudes Na-Pa em $\mu \mathrm{v}$ entre as modalidades C3/A1 e C4/A1, e entre C3/A2 e C4/A2 do PEAML, no grupo controle

\begin{tabular}{|c|c|c|c|c|}
\hline \multirow{2}{*}{$\begin{array}{c}\text { PEAML (Controle) } \\
\text { Amplitude Na-Pa em } \mu v\end{array}$} & \multicolumn{2}{|c|}{ A1 } & \multicolumn{2}{|c|}{ A2 } \\
\hline & C3 & C4 & C3 & C4 \\
\hline Média & 1,32 & 1,21 & 1,21 & 1,44 \\
\hline Mediana & 1,61 & 1,76 & 1,48 & 1,63 \\
\hline Desvio Padrão & 0,54 & 0,50 & 0,46 & 0,68 \\
\hline Mínimo & 0,51 & 0,27 & 0,32 & 0,43 \\
\hline Máximo & 3,51 & 2,12 & 2,13 & 3,12 \\
\hline Tamanho & 25 & 25 & 25 & 25 \\
\hline Limite Inferior & 0,85 & 0,72 & 0,83 & 0,85 \\
\hline Limite Superior & 1,83 & 1,64 & 1,44 & 1,84 \\
\hline p-valor & \multicolumn{2}{|c|}{0,280} & \multicolumn{2}{|c|}{0,366} \\
\hline $\begin{array}{l}\text { C3 }=\text { junção têmporo-parietal esquerda } \\
C 4=\text { junção têmporo-parietal direita } \\
\text { A1 }=\text { mastóide esquerda } \\
\text { A2 }=\text { mastóide direita } \\
\text { AV }=\text { microvolt } \\
\text { SEAML = Potencial Evocado Auditivo }\end{array}$ & & & & \\
\hline
\end{tabular}

Na tabela 12 não foi observada diferença estatisticamente significante para as amplitudes $\mathrm{Na}-\mathrm{Pa}$ entre as modalidades C3/A1 e C4/A1, e entre C3/A2 e C4/A2, no grupo controle. 
TABELA 13 - Comparação dos valores médios das amplitudes Na-Pa em $\mu \mathrm{v}$ entre as modalidades C3/A1 e C4/A1, e entre C3/A2 e C4/A2 do PEAML, no grupo pesquisa

\begin{tabular}{|c|c|c|c|c|}
\hline \multirow{2}{*}{$\begin{array}{c}\text { PEAML (Pesquisa) } \\
\text { Amplitude Na-Pa em } \mu v\end{array}$} & \multicolumn{2}{|c|}{ A1 } & \multicolumn{2}{|c|}{ A2 } \\
\hline & C3 & $\mathrm{C} 4$ & C3 & $\mathrm{C4}$ \\
\hline Média & 1,99 & 1,96 & 3,33 & 1,51 \\
\hline Mediana & 1,45 & 1,84 & 1,62 & 1,45 \\
\hline Desvio Padrão & 1,48 & 0,87 & 4,61 & 0,63 \\
\hline Mínimo & 0,64 & 0,70 & 0,43 & 0,56 \\
\hline Máximo & 5,72 & 3,71 & 15,66 & 2,39 \\
\hline Tamanho & 25 & 25 & 25 & 25 \\
\hline Limite Inferior & 1,27 & 1,53 & 1,07 & 1,19 \\
\hline Limite Superior & 2,71 & 2,38 & 5,59 & 1,82 \\
\hline p-valor & \multicolumn{2}{|c|}{0,938} & \multicolumn{2}{|c|}{0,128} \\
\hline 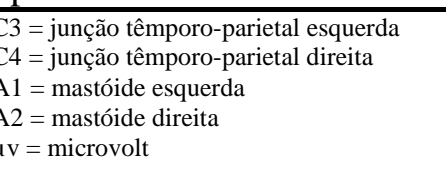 & & & & \\
\hline
\end{tabular}

No grupo pesquisa, conforme evidenciado na Tabela 13, também não ocorreu diferença estatisticamente significante para as amplitudes $\mathrm{Na}-\mathrm{Pa}$ entre as modalidades C3/A1 e C4/A1, e entre C3/A2 e C4/A2 do PEAML.

Não foram agrupadas as orelhas e os hemisférios, visto que o objetivo foi comparar a amplitude Na-Pa obtida em cada modalidade (C3/A1, C3/A2, C4/A1, e C4/A2) do PEAML.

A seguir foram comparadas as amplitudes $\mathrm{Na}-\mathrm{Pa}$, para cada modalidade (C3/A1, C3/A2, C4/A1, C4/A2), entre os grupos controle e pesquisa. 
TABELA 14 - Comparação dos valores médios das amplitudes Na-Pa em $\mu \mathrm{v}$ nas modalidades C3/A1, C3/A2, C4/A1, C4/A2 do PEAML, entre os grupos controle e pesquisa

\begin{tabular}{|c|c|c|c|c|c|c|c|c|}
\hline \multirow{2}{*}{$\begin{array}{l}\text { Amp. Na- } \\
\text { Pa em pv } \\
\text { PEAML }\end{array}$} & \multicolumn{2}{|c|}{ C3/A1 } & \multicolumn{2}{|c|}{ C3/A2 } & \multicolumn{2}{|c|}{ C4/A1 } & \multicolumn{2}{|c|}{ C4/A2 } \\
\hline & Controle & Pesquisa & Controle & Pesquisa & Controle & Pesquisa & Controle & Pesquisa \\
\hline Média & 2,57 & 1,99 & 4,23 & 3,33 & 3,43 & 1,96 & 2,00 & 1,51 \\
\hline Mediana & 1,61 & 1,45 & 1,48 & 1,62 & 1,76 & 1,84 & 1,63 & 1,45 \\
\hline $\begin{array}{l}\text { Desvio } \\
\text { Padrão } \\
\end{array}$ & 3,76 & 1,48 & 10,95 & 4,61 & 7,69 & 0,87 & 1,92 & 0,63 \\
\hline Mínimo & 0,25 & 0,64 & 0,53 & 0,43 & 0,64 & 0,70 & 0,34 & 0,56 \\
\hline Máximo & 19,93 & 5,72 & 55,95 & 15,66 & 39,91 & 3,71 & 10,20 & 2,39 \\
\hline Tamanho & 25 & 25 & 25 & 25 & 25 & 25 & 25 & 25 \\
\hline $\begin{array}{l}\text { Limite } \\
\text { Inferior }\end{array}$ & 1,09 & 1,27 & $-0,07$ & 1,07 & 0,42 & 1,53 & 1,24 & 1,19 \\
\hline $\begin{array}{l}\text { Limite } \\
\text { Superior }\end{array}$ & 4,05 & 2,71 & 8,52 & 5,59 & 6,45 & 2,38 & 2,75 & 1,82 \\
\hline $\mathrm{p}$-valor & \multicolumn{2}{|c|}{0,561} & \multicolumn{2}{|c|}{0,759} & \multicolumn{2}{|c|}{0,451} & \multicolumn{2}{|c|}{0,331} \\
\hline
\end{tabular}

C3 = junção têmporo-parietal esquerda

C4 = junção têmporo-parietal direita

$\mathrm{A} 1$ = mastóide esquerda

$\mathrm{A} 2$ = mastóide direita

$\mu \mathrm{v}=$ microvolt

PEAML = Potencial Evocado Auditivo de Média Latência

$\mathrm{Na}$ tabela 14 não foram observadas diferenças estatisticamente significantes entre os grupos controle e pesquisa para a amplitude $\mathrm{Na}-\mathrm{Pa}$, nas quatro modalidades estudadas (C3/A1, C3/A2, C4/A1, e C4/A2) do PEAML.

A seguir foi realizada a análise dos dados qualitativos, comparando-se os resultados normais e alterados obtidos para as latências das ondas $\mathrm{Na}$ e Pa e amplitude Na-Pa do PEAML, para cada grupo avaliado e entre os grupos (Tabela 15, 16 e 17). 
TABELA 15 - Distribuição da ocorrência de resultados normais e alterados para a latência da onda $\mathrm{Na}$ do PEAML, nos grupos controle e pesquisa

\begin{tabular}{|c|c|c|c|c|c|c|c|}
\hline \multirow{2}{*}{$\begin{array}{c}\text { Latência } \\
\text { da Onda } \\
\text { Na }\end{array}$} & \multicolumn{3}{|c|}{ Grupo Controle } & \multicolumn{3}{|c|}{ Grupo Pesquisa } & \multirow{2}{*}{ p-valor } \\
\hline & $\mathbf{N}$ & $\%$ & var & $\mathbf{N}$ & $\%$ & var & \\
\hline Normal & 21 & $84 \%$ & \multirow{2}{*}{$40 \%$} & 2 & $8 \%$ & \multirow{2}{*}{$42,8 \%$} & \multirow{2}{*}{$0,007 *$} \\
\hline Alterado & 4 & $16 \%$ & & 23 & $92 \%$ & & \\
\hline p-valor & & $0,008 *$ & & & 0,005 & & \\
\hline
\end{tabular}

* p-valor considerado estatisticamente significante

$\mathrm{N}=$ número de indivíduos

Var = índice de variação em relação à média

TABELA 16 - Distribuição da ocorrência de resultados normais e alterados para a latência da onda $\mathrm{Pa}$ do PEAML, nos grupos controle e pesquisa

\begin{tabular}{|c|c|c|c|c|c|c|c|}
\hline \multirow{2}{*}{$\begin{array}{c}\text { Latência } \\
\text { da Onda } \\
\text { Pa }\end{array}$} & \multicolumn{3}{|c|}{ Grupo Controle } & \multicolumn{3}{|c|}{ Grupo Pesquisa } & \multirow{2}{*}{ p-valor } \\
\hline & $\mathbf{N}$ & $\%$ & var & $\mathbf{N}$ & $\%$ & var & \\
\hline Normal & 20 & $80 \%$ & \multirow{2}{*}{$45 \%$} & 23 & $8 \%$ & \multirow{2}{*}{$42,8 \%$} & \multirow{2}{*}{0,076} \\
\hline Alterado & 5 & $20 \%$ & & 2 & $92 \%$ & & \\
\hline p-valor & & $0,006^{*}$ & & & $0,005^{*}$ & & \\
\hline
\end{tabular}

* p-valor considerado estatisticamente significante

$\mathrm{N}$ = número de indivíduos

Var = índice de variação em relação à média 
Pode-se observar, na Tabela 15, que ocorreu diferença estatisticamente significante entre os resultados normal e alterado para a latência da onda $\mathrm{Na}$, nos grupos controle e pesquisa. Por sua vez, para a latência da onda $\mathrm{Pa}$, também foram observadas na Tabela 16 diferenças estatisticamente significantes entre os resultados normal e alterado, tanto no grupo controle como no grupo pesquisa.

Vale ressaltar que, para todos os resultados alterados, o tipo de alteração encontrada foi atraso de latência das ondas.

TABELA 17 - Distribuição da ocorrência de resultados normais e alterados para a amplitude Na-Pa do PEAML, nos grupos controle e pesquisa

\begin{tabular}{|c|c|c|c|c|c|c|c|}
\hline \multirow{2}{*}{ Tabela 17} & \multicolumn{3}{|c|}{ Grupo Controle } & \multicolumn{3}{|c|}{ Grupo Pesquisa } & \multirow{2}{*}{ p-valor } \\
\hline & $\mathbf{N}$ & $\%$ & var & $\mathbf{N}$ & $\%$ & var & \\
\hline Normal & 18 & $72 \%$ & \multirow{2}{*}{$32 \%$} & 11 & $44 \%$ & \multirow{2}{*}{$29,7 \%$} & \multirow{2}{*}{0,157} \\
\hline Alterado & 7 & $28 \%$ & & 14 & $56 \%$ & & \\
\hline p-valor & & 0,589 & & & 0,157 & & \\
\hline
\end{tabular}

* $\mathrm{p}$-valor considerado estatisticamente significante

$\mathrm{N}=$ número de indivíduos

Var = índice de variação em relação à média 
Pode-se observar na tabela 17 que não ocorreu diferença estatisticamente significante entre os resultados normal e alterado nos grupos controle e pesquisa para amplitude $\mathrm{Na}-\mathrm{Pa}$. $\mathrm{Na}$ comparação entre os grupos controle e pesquisa, verificou-se também que não ocorreu diferença estatisticamente significante para os resultados normal e alterado.

$\mathrm{Na}$ tabela 18, foram comparadas as alterações encontradas no PEAML entre os grupos controle e pesquisa, e em um mesmo grupo. 
TABELA 18 - Distribuição dos tipos de alterações encontradas para a amplitude Na-Pa do PEAML, nos grupos controle e pesquisa

\begin{tabular}{ccccc}
\hline Alterações & & Controle & Pesquisa & p-valor \\
\hline \multirow{2}{*}{ Efeito orelha } & $\mathrm{N}$ & 2 & 5 & \multirow{2}{*}{0,286} \\
\cline { 2 - 4 } & $\%$ & $28,5 \%$ & $36 \%$ & \\
\hline \multirow{2}{*}{ Efeito eletrodo } & $\mathrm{N}$ & 2 & 5 & \multirow{2}{*}{0,286} \\
\cline { 2 - 4 } & $\%$ & $28,5 \%$ & $36 \%$ & 0,257 \\
\hline \multirow{2}{*}{ Ambas } & $\mathrm{N}$ & 3 & 4 & \\
\cline { 2 - 4 } & $\%$ & $43 \%$ & $28 \%$ & \\
\hline
\end{tabular}

\begin{tabular}{lccc}
\hline & Alterações & Efeito orelha & Efeito eletrodo \\
\hline \multirow{2}{*}{ Controle } & Efeito eletrodo & 0,286 & -- \\
\cline { 2 - 4 } & Ambas & 0,589 & 0,931 \\
\hline \multirow{2}{*}{ Pesquisa } & Efeito eletrodo & 0,076 & - \\
\cline { 2 - 4 } & Ambas & 0,115 & 0,115 \\
\hline
\end{tabular}

* $p$-valor considerado estatisticamente significante

$\mathrm{N}=$ número de indivíduos

Var = índice de variação em relação à média

Conforme descrito na tabela 18, não houve diferença estatisticamente significante entre os grupos, a qual pudesse ser considerada estatisticamente significante, em quaisquer dos tipos de alterações. A alteração mais freqüente no grupo controle foi do tipo Ambas (43\%) e no grupo pesquisa foram de dois tipos: efeito orelha (36\%) e efeito eletrodo (36\%). 


\section{Parte III - Resultados do Potencial Cognitivo nos grupos controle} e pesquisa.

Iniciou-se a análise do P300 ou Potencial Cognitivo comparando as orelhas direita e esquerda em cada grupo estudado. Foram comparados os valores de latência da onda P300 entre as orelhas direita e esquerda, nos grupos controle e pesquisa.

TABELA 19- Comparação dos valores médios das latências do P300 em ms entre as orelhas direita e esquerda, no grupo controle

\begin{tabular}{lcc}
\hline \multicolumn{1}{c}{ P300 (Controle) latência(ms) } & OD & OE \\
\hline Média & 311,82 & 315,52 \\
\hline Mediana & 306,95 & 315,76 \\
\hline Desvio Padrão & 21,85 & 13,93 \\
\hline Mínimo & 243,53 & 290,55 \\
\hline Máximo & 347,61 & 351,99 \\
\hline Tamanho & 25 & 25 \\
\hline Limite Inferior & 300,24 & 304,58 \\
\hline Limite Superior & 329,91 & 321,64 \\
\hline p-valor & & 0,133 \\
\hline
\end{tabular}

$\mathrm{OD}=$ Orelha Direita.

$\mathrm{OE}=$ Orelha Esquerda

Ms $=$ milissegundos

P300 = Potencial Cognitivo 
$\mathrm{Na}$ tabela 19 não foram observadas diferenças estatisticamente significantes nas latências do P300 entre as orelhas direita e esquerda, no grupo controle.

TABELA 20 - Comparação dos valores médios das latências do P300 em ms entre as orelhas direita e esquerda, no grupo pesquisa

\begin{tabular}{lcc}
\hline \multicolumn{1}{c}{ P300 (Pesquisa) latência (ms) } & OD & OE \\
\hline Média & 316,49 & 307,82 \\
\hline Mediana & 315,78 & 301,90 \\
\hline Desvio Padrão & 34,24 & 33,41 \\
\hline Mínimo & 246,92 & 257,75 \\
\hline Máximo & 382,90 & 390,20 \\
\hline Tamanho & 25 & 25 \\
\hline Limite Inferior & 295,60 & 287,71 \\
\hline Limite Superior & 382,69 & 326,92 \\
\hline p-valor & & 0,734 \\
\hline
\end{tabular}

$\mathrm{OD}=$ Orelha Direita.

$\mathrm{OE}=$ Orelha Esquerda

$\mathrm{ms}=$ milissegundos

P300 = Potencial Cognitivo

No grupo pesquisa, conforme descrito na Tabela 20, também não evidenciou-se diferenças estatisticamente significantes nas latências do P300 entre as orelhas direita e esquerda.

Como não ocorreram diferenças médias estatisticamente significantes entre as orelhas direita e esquerda, nos grupos controle e pesquisa, para a latência do P300, os valores obtidos nas orelhas direita e esquerda foram agrupados. Desta forma, as próximas análises foram realizadas considerando um total de 50 orelhas. 
Ainda considerando-se a análise dos dados quantitativos, foram comparadas a seguir as latências da onda P300 entre os grupos controle e pesquisa.

TABELA 21 - Comparação dos valores médios das latências do P300 em ms entre os grupos controle e pesquisa

\begin{tabular}{lcc}
\hline \multicolumn{1}{c}{ P300 (lat.) } & Controle & Pesquisa \\
\hline Média & 313,27 & 312,24 \\
\hline Mediana & 311,27 & 311,99 \\
\hline Desvio Padrão & 18,19 & 33,78 \\
\hline Mínimo & 243,53 & 246,92 \\
\hline Máximo & 351,99 & 390,20 \\
\hline Tamanho & 50 & 50 \\
\hline Limite Inferior & 302,63 & 292,44 \\
\hline $\begin{array}{l}\text { Limite Superior } \\
\text { p-valor }\end{array}$ & 325,28 & 329,02 \\
\hline $\begin{array}{l}\text { OD }=\text { Orelha Direita. } \\
\text { OE = Orelha Esquerda } \\
\text { ms = milissegundos } \\
\text { lat. = latência } \\
\text { P300 Potencial Evocado Auditivo de de longa latência ou cognitivo }\end{array}$ & \\
\hline
\end{tabular}

Na comparação entre os grupos controle e pesquisa, conforme descrito na Tabela 21, não evidenciou-se diferenças médias consideradas estatisticamente significantes para a latência da onda P300.

A seguir foi realizada a análise dos dados qualitativos, comparando-se os resultados normais e alterados obtidos no $\mathrm{P} 300$, para cada grupo avaliado e entre os grupos (Tabela 22). 
TABELA 22 - Distribuição da ocorrência de resultados normais e alterados no P300, nos grupos controle e pesquisa

\begin{tabular}{|c|c|c|c|c|c|c|c|}
\hline \multirow{2}{*}{ P300 } & \multicolumn{3}{|c|}{ Grupo Controle } & \multicolumn{3}{|c|}{ Grupo Pesquisa } & \multirow{2}{*}{ p-valor } \\
\hline & $\mathbf{N}$ & $\%$ & var & $\mathbf{N}$ & $\%$ & var & \\
\hline Normal & 25 & $100,0 \%$ & \multirow{2}{*}{$0,0 \%$} & 14 & $56 \%$ & \multirow{2}{*}{$22,7 \%$} & \multirow{2}{*}{$0,003 *$} \\
\hline Alterado & 0 & $0,0 \%$ & & 11 & $44 \%$ & & \\
\hline p-valor & & $<0,001 *$ & & & $0,034 *$ & & \\
\hline
\end{tabular}

Nesta análise observou-se diferença estatisticamente significante entre os resultados normal e alterado nos grupos controle e pesquisa. $\mathrm{Na}$ comparação entre os grupos controle e pesquisa, verificou-se também diferença estatisticamente significante para os resultados normal e alterado.

Na tabela 23 foram comparadas as alterações encontradas no P300 entre os grupos controle e pesquisa, e em um mesmo grupo. 
TABELA 23 - Distribuição dos tipos de alterações encontradas no P300, nos grupos controle e pesquisa

\begin{tabular}{ccccc}
\hline Alterações & & Controle & Pesquisa & p-valor \\
\hline \multirow{2}{*}{ Atraso de latência } & $\mathrm{N}$ & 0 & 10 & - - \\
\cline { 2 - 4 } & $\%$ & $0,0 \%$ & $40,0 \%$ & \\
\hline $\begin{array}{c}\text { Ausência de } \\
\text { resposta }\end{array}$ & $\mathrm{N}$ & 0 & 1 & - - \\
\cline { 2 - 4 } Ambas & $\%$ & $0,0 \%$ & $4,0 \%$ & \\
\hline & $\%$ & 0 & 0 & - \\
\hline
\end{tabular}

\begin{tabular}{cccc}
\hline \multirow{2}{*}{ Controle } & Alterações & $\begin{array}{c}\text { Atraso de } \\
\text { latência }\end{array}$ & $\begin{array}{c}\text { Ausência de } \\
\text { resposta }\end{array}$ \\
\cline { 2 - 4 } & Atraso de latência & -- & - \\
\cline { 2 - 4 } Pesquisa & Ambas & -- & - \\
\cline { 2 - 4 } & Atraso de latência & -- & $0,03 *$ \\
\hline \multirow{2}{*}{ Ambas } & $0,009 *$ & 0,057 \\
\hline
\end{tabular}

* $\mathrm{p}$-valor considerado estatisticamente significante

p-valores

$\mathrm{N}=$ número de indivíduos

Var = índice de variação em relação a média

Devido ao fato do grupo controle não ter apresentado resultados alterados no P300, não houve possibilidade de realizar a comparação dos tipos de alterações entre os grupos.

Verificou-se que o atraso de latência da onda P300 foi a alteração mais freqüente no grupo pesquisa (40\%), sendo considerada estatisticamente significante em relação aos demais tipos de alterações (ausência de resposta) . 



\section{Discussão}




\section{6 - DISCUSSÃO}

A Esclerose Múltipla (EM) ou Doença Desmielinizante, caracterizada por alterações das funções encefálicas decorrentes da diminuição da velocidade dos impulsos nervosos, é provocada pela destruição do envoltório mielínico. As lesões da EM causam uma grande variedade de sinais e sintomas iniciais que aparecem isolados ou de maneira combinada.

A EM pode lesionar o Sistema Nervoso Central e deve-se lembrar que a sensibilidade auditiva depende da integridade do mesmo. A literatura evidencia que um diagnóstico audiológico baseado apenas em uma avaliação audiológica convencional em pacientes com EM não é eficiente, visto que muitas alterações ocorrem ao longo da via auditiva central (Collard et al., 1969; Noffsinger et al., 1972; Fisher et al., 1984; Mustillo, 1984; Jerger et al., 1986).

Os PEA, segundo Stach (1998), são respostas eletrofisiológicas obtidas frente ao estímulo acústico e podem ser classificadas de acordo com a latência: latência breve ou curta correspondendo à eletrococleografia e PEATE, latência média $(P E A M L)$ e longa latência (PEALL), este último incluindo o P300, sendo utilizados para determinar o limiar de detecção do sinal acústico e inferir sobre a integridade funcional e estrutural dos componentes neurais da via auditiva (Kraus et al., 1999). Portanto, são 
importantes para avaliar a sincronia neural, uma vez que é uma habilidade do sistema nervoso auditivo em responder sincronicamente a uma estimulação sonora (Hood, 1995).

Para tanto, no presente estudo realizou-se a avaliação eletrofisiológica da audição por meio dos PEA de curta, média e longa latências em indivíduos com EM, reafirmando a importância da aplicação dos PEA na neurociência por fornecerem uma medida objetiva sobre a integridade do sistema auditivo como um todo (Rao et al., 1991)

Para a análise dos resultados o trabalho se apoiou no conceito de McPherson e Starr (1993), que ressaltam que os PEA podem ser caracterizados de acordo com o tempo em que ocorrem, conhecido como latência, sendo que aumentos nestas respostas (latências) são evidências objetivas de problemas clínicos e/ou sub-clínicos.

O primeiro potencial analisado neste trabalho foi o PEATE, que avaliou a integridade da via auditiva no tronco encefálico, permitindo assim a identificação de possíveis alterações neste trajeto. Foram identificadas as ondas I, III e V e analisados seus tempos de latência absoluta e os intervalos de ocorrência entre elas (I-III, III-V e I-V). Musiek et al.(1999) enfatizaram que estas medidas do PEATE são muito importantes no auxílio do neurodiagnóstico, pois verificam a existência de alterações tanto estruturais 
como funcionais na transmissão do estímulo acústico do nervo auditivo ao tronco encefálico.

Para a coleta dos potenciais deve-se lembrar que participaram desta pesquisa 25 sujeitos com diagnóstico definido de EM do tipo remitente recorrente e 25 indivíduos normais sem histórico de doenças neurológicas, de ambos os sexos e com idade variando de 25 a 55 anos.

Ressalta-se que foram excluídos do estudo indivíduos que apresentaram algum tipo de perda auditiva, sendo que tal exclusão foi baseada em um estudo realizado por Melaragno (1992), que afirma ser pouco freqüente o aparecimento de placas desmielinizadas no VIII nervo, sendo portanto raro o aparecimento de deficiência auditiva em indivíduos com EM.

$\mathrm{Na}$ análise dos dados quantitativos, ao ser realizada a comparação das latências absolutas das ondas I, III e V e dos interpicos I-III, III-V e I-V entre as orelhas direita e esquerda, nos grupos controle e pesquisa, não foi observada diferença estatisticamente significante (Tabelas 1 e 2). $\mathrm{Na}$ comparação dos resultados obtidos no PEATE entre os grupos controle e pesquisa, observou-se diferença estatisticamente significante com aumento nas latências absolutas das ondas III e V e nos interpicos I-III e I-V para o grupo pesquisa (Tabela 3). 
Por sua vez, na análise dos dados qualitativos, verificou-se diferença estatisticamente significante na distribuição da ocorrência de resultados normais e alterados no PEATE, sendo que o grupo pesquisa apresentou uma maior porcentagem de resultados alterados (68\%) quando comparado com o grupo controle (Tabela 4), dados semelhantes aos obtidos por Celebisoy et al. (1996), que observaram alteração no PEATE em 60\% dos indivíduos avaliados portadores de EM

Tais análises sugerem a presença de alteração na via auditiva em tronco encefálico baixo em indivíduos com EM, conforme evidenciado na Tabela 5, concordando com o estudo de Bergamashi et al. (1997) que verificaram a presença de alteração na porção distal do nervo auditivo em pacientes com EM, dados confirmados por imagens de ressonância magnética. Estes resultados corroboram também os obtidos no estudo de Schochat et al. (2006) que, ao relatar o caso de um indivíduo com EM, evidenciaram alteração em tronco encefálico baixo devido à ausência da onda III e atraso na latência absoluta da onda V no PEATE.

A presença de alterações no PEATE em indivíduos com EM também pode ser evidenciada no estudo de Santos et al. (2003) que, avaliando a incidência de comprometimento auditivo em indivíduos com diagnóstico definido de EM, sem sinais clínicos ou de alterações à ressonância nuclear magnética de acometimento do tronco encefálico, obtiveram alterações no PEATE em $60 \%$ dos indivíduos do gênero feminino e $56 \%$ do masculino, 
perfazendo $58,62 \%$ do total de indivíduos avaliados. Os tipos de alterações encontradas foram prejuízo na morfologia das ondas, aumento do interpico IV, presença somente da onda I ou ausência das últimas ondas apresentando as primeiras latências absolutas normais.

Portanto, os dados encontrados nesta pesquisa e nos estudos de Palace (2001) e Santos et al. (2003) enfatizam a importância da realização dos PEATE em casos de indivíduos com suspeita clínica de doenças desmielinizantes e, principalmente, com diagnóstico comprovado de Esclerose, auxiliando desta forma tanto no diagnóstico como na definição do tipo de comprometimento encefálico apresentado pelo indivíduo.

Contudo, Palace (2001) relata que o PEATE é um teste muitas vezes dispensado em vários centros de diagnóstico por apresentar uma menor sensibilidade na detecção de alterações em indivíduos com EM visto que avalia a via auditiva apenas até o tronco encefálico, não detectando lesões em outras áreas subcorticais e corticais auditivas, lesões estas muito comuns em casos deEM.

O segundo potencial analisado neste trabalho foi o PEAML, que aparece após o PEATE como um conjunto de ondas positivas e negativas com latências entre 10 e 80ms, tendo como geradores a via auditiva tálamocortical, formação reticular mesencefálica, colículo inferior e córtex auditivo (Musiek e Geurkink, 1981 e Kraus et al., 1999). Para a análise deste 
potencial identificou-se as ondas $\mathrm{Na}, \mathrm{Pa}, \mathrm{Nb}$ e $\mathrm{Pb}$, por serem as maiores em amplitude, mais consistentes e estáveis.

O PEAML é considerado um dos melhores exames para avaliar o sistema nervoso auditivo central e os distúrbios do processamento auditivo, sendo também uma ferramenta útil para direcionar técnicas de terapia de linguagem e auxiliar no monitoramento terapêutico.

$\mathrm{Na}$ análise dos dados quantitativos, ao ser realizada a comparação das latências das ondas $\mathrm{Na}$ e $\mathrm{Pa}$ e da amplitude $\mathrm{Na}-\mathrm{Pa}$ entre as modalidades C3/A1 e C3/A2 e entre C4/A1 e C4/A2, nos grupos controle e pesquisa, não foram evidenciadas diferenças estatisticamente significantes (Tabelas 6, 7, 8, 9, 10, 11, 12 e 13).

Por sua vez, na distribuição da ocorrência de resultados normais e alterados no PEAML (análise qualitativa), o grupo pesquisa apresentou uma maior porcentagem de resultados alterados (92\%) quando comparado com o grupo controle (16\%) para a latência da onda Na (Tabela 15), sendo que a mesma porcentagem de resultados alterados foi observada no grupo pesquisa para a latência da onda $\mathrm{Pa}$ (Tabela 16). O tipo de alteração mais encontrada foi o atraso nas latências das ondas $\mathrm{Na}$ e Pa. 
No estudo da amplitude Na-Pa não ocorreu diferença estatisticamente significante entre os resultados normais e alterados no grupo pesquisa, porém neste grupo houve uma maior porcentagem de resultados alterados (56\% dos casos) quando comparado com o grupo controle (28\% dos casos) (Tabela 17).

O tipo de alteração encontrado mais freqüentemente no grupo controle foi a do tipo Ambas (43\%) e no grupo pesquisa foram o efeito orelha (36\%) e o efeito eletrodo (36\%) (Tabela 18).

$\mathrm{Na}$ literatura consultada existem poucos trabalhos que tenham utilizado como medida eletrofisiológica o PEAML, junto com outros PEA, para a investigação da via auditiva em indivíduos portadores de EM. A presença de alterações no PEAML em indivíduos portadores de EMtambém pode ser evidenciada, assim como na presente pesquisa, no estudo de Celebisoy et al. (1996) que observaram em 73,4\% dos casos avaliados alteração no PEAML. Em um estudo de caso de EM apresentado por Schochat et al. (2006), o PEAML encontrou-se comprometido, assim como o PEATE, demonstrando desta forma a possibilidade de comprometimento da via auditiva no tronco encefálico e em nível subcortical na EM.

O terceiro e último potencial analisado neste trabalho foi o potencial evocado auditivo de longa latência P300, também denominado potencial cognitivo, descrito inicialmente por Sutton (1965). Este potencial apresenta 
como geradores o córtex frontal, córtex centroparietal e hipocampo (McPherson, 1996) e sofre influências de algumas variáveis como idade, gênero, habilidades cognitivas, sendo portanto um instrumento útil no diagnóstico de disfunções cognitivas (Polich, 1991).

$\mathrm{Na}$ presente pesquisa utilizou-se como parâmetro de medida a latência da onda P300 que, segundo Picton (1992), é o indicador mais fidedigno para análise deste potencial.

Analisando os dados quantitativamente, na comparação das latências do P300 entre as orelhas direita e esquerda, nos grupos controle e pesquisa, não foi observada diferença estatisticamente significante (Tabelas 19 e 20). Na comparação das latências do P300 entre os grupos controle e pesquisa também não foi evidenciada diferença estatisticamente significante entre os grupos (Tabela 21).

Por outro lado, na análise qualitativa, ao ser analisada a distribuição da ocorrência de resultados normais e alterados no P300, nos grupos controle e pesquisa, verificou-se diferença estatisticamente significante, ou seja, o grupo pesquisa apresentou uma maior porcentagem de resultados alterados (44\%) quando comparado com o grupo controle, que apresentou 100\% de resultados normais (Tabela 22). O tipo de alteração mais frequentemente observada no grupo pesquisa foi o atraso na latência do P300 (Tabela 23). 
Na literatura consultada encontraram-se vários trabalhos (Rao et al., 1991; Giesser et al., 1992; Fischer, 2000; Gonzáles-Rosa et al., 2006 e Magnano et al., 2006) que referem a presença de alterações cognitivas em pacientes com EM, demonstrando que estes podem apresentar alterações na memória, atenção, fluência verbal, execução de tarefas e percepção visual, o que poderia comprometer a resposta no P300. Tais dados justificam plenamente a utilização deste potencial auxiliando no diagnóstico e acompanhamento da evolução da EM, conforme relatado por Kurokawa et al. (2003) e Magnano et al. (2006).

$\mathrm{Na}$ EM, as avaliações eletrofisiológicas do SNC, realizadas por meio dos potenciais evocados visuais, auditivos de curta latência e somatossensitivos, encontram-se bem estabelecidas. Por sua vez, os PEA relacionados a eventos têm sido amplamente estudados devido à sua correlação com aspectos cognitivos. As alterações encontradas nestes potenciais são definidas pelo prolongamento das ondas ou pela ausência de formação dos picos característicos (Santos et al., 2006). 
Os achados encontrados nesta pesquisa referentes à presença de alterações no P300 em indivíduos com EM, bem como ao tipo de alteração mais freqüentemente encontrada neste potencial, ou seja, atraso na latência da onda P300, são compatíveis com os obtidos por Newton et al. (1989), Giesser et al. (1992), Gil et al. (1992), Dijk et al. (1992), Gonzáles-Rosa et al. (2006), Magnano et al. (2006) e Schochat et al. (2006). 


\section{Considerações Finais}




\section{7 - CONSIDERAÇÕES FINAIS}

Na presente pesquisa observaram-se alterações nos PEATE, PEAML e P300 em indivíduos com EM do tipo remitente recorrente, sugerindo comprometimento das estruturas geradoras destes potenciais ao longo do sistema nervoso auditivo central, provavelmente pela presença de placas escleróticas em diferentes locais deste sistema.

Levando-se em consideração estes aspectos, acreditamos que a associação de diferentes métodos objetivos de avaliação eletrofisiológica da audição (PEATE, PEAML e P300) permite-nos aumentar a sensibilidade para detecção de alterações na via auditiva central, em indivíduos com EM. 


\section{Conclusão}




\section{CONCLUSÃO}

Os resultados obtidos no presente estudo permitem-nos concluir que indivíduos com Esclerose Múltipla do tipo remitente recorrente apresentam:

$\checkmark \quad$ alterações no potencial evocado auditivo de tronco encefálico sugerindo:

o comprometimento da via auditiva em tronco encefálico nas regiões do núcleo coclear ao lemnisco lateral;

o alterações estruturais e/ou funcionais na transmissão do estímulo acústico ao longo da via auditiva;

$\checkmark \quad$ alterações no potencial evocado auditivo de média latência sugerindo:

o comprometimento da via auditiva em regiões subcorticais;

o distúrbio do processamento auditivo;

$\checkmark \quad$ alterações no potencial cognitivo sugerindo:

o comprometimento da via auditiva em regiões corticais;

o déficit no processamento cognitivo;

o déficit de memória;

o déficit de atenção;

o déficit na discriminação auditiva. 
Anexos 


\section{ANEXO A}

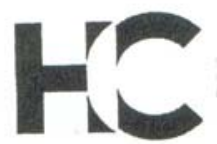

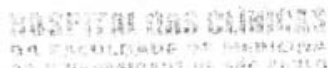

Anexo A

\section{APROVAÇÃO}

A Comissão de Ética para Análise de Projetos de Pesquisa - CAPPesq da Diretoria Clínica do Hospital das Clínicas e da Faculdade de Medicina da Universidade de São Paulo, em sessão de 01/08/2007, APROVOU o Protocolo de Pesquisa $n^{\circ}$ 0318/07, intitulado: "POTENCIAIS EVOCADOS AUDITIVOS E ESCLORESE MÚLTIPLA" apresentado pelo DEPARTAMENTO DE, FISIOTERAPIA, FONOAUDIOLOGIA E TERAPIA OCUPACIONAL, inclusive O Termo de Consentimento Livre e Esclarecido.

Cabe ao pesquisador elaborar e apresentar à CAPPesq, os relatórios parciais e final sobre a pesquisa (Resolução do Conselho Nacional de Saúde $n^{\circ} 196$, de 10/10/1996, inciso IX.2, letra "c").

* Pesquisador (a) Responsável: Prof ${ }^{a}$. Dra . Carla Gentile Matas * Pesquisador (a) Executante: Caroline Rondina Salzano de OLiveira CAPPesq, 08 de Agosto de 2007 Ean

Prof. Dr. Eduardo Massad Presidente da Comissão $11+4$ de Ética para Análise de Projetos de Pesquisa

\footnotetext{
Comissẫo de Ética para Análise de Projetos de Pesquisa do HCFMUSP e da FMUSP Diretoria Clínica do Hospital das Clinicas da Faculdade de Medicina da Universidade de Săo Paulo Rua Ovidio Pires de Campos. 255, 5 andar - CEP 05403010 - Săo Paulo - SP Fone: 01130696442 Fax: 01130696492 e-mail: cappesq@hcnet.usp.br/ secretariacappesq2@hcnet.usp.br - fe
} 


\section{ANEXO B}

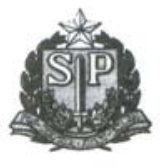

HOSPITAL DAS CLÍNICAS

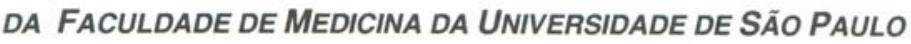

CAIXA POSTAL, 8091 - SÃo PAULO - BRAsIL

TERMO DE CONSENTIMENTO LIVRE E ESCLARECIDO

AnexoB

(Instruçōes para preenchimento no verso)

I - DADOS DE IDENTIFICAÇÃO DO SUJEITO DA PESQUISA OU RESPONSÁVEL LEGAL

1. NOME DO PACIENTE :

DOCUMENTO DE IDENTIDADE № :

SEXO: M $\square$ F

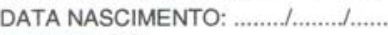

ENDERECCO

BAIRRO:

$\mathrm{N}^{2}$

APTO:

CEP:

TELEFONE: DDD (

CIDADE

2.RESPONSÁVEL LEGAL

NATUREZA (grau de parentesco, tutor, curador etc.)

DOCUMENTO DE IDENTIDADE

DATA NASCIMENTO.: ......................

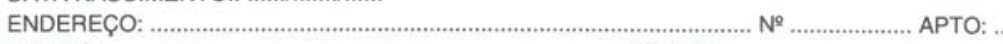

BAIRRO:

CEP: …….......................... TELEFONE: DDD (.............

II - DADOS SOBRE A PESQUISA CIENTÍFICA

1. TÍTULO DO PROTOCOLO DE PESQUISA

"POTENCIAIS EVOCADOS AUDITIVOS E ESCLEROSE MÚLTIPLA"

PESQUISADOR: Caroline Rondina Salzano de Oliveira

CARGO/FUNÇĀO: pós-graduanda (mestrado) INSCRIÇĀO CONSELHO REGIONAL № CRFa. 13740

UNIDADE DO HCFMUSP:

3. AVALIAÇÃO DO RISCO DA PESQUISA:

$\begin{array}{lll}\text { SEM RISCO } & \text { RISCO MINIMO } X & \text { RISCO MÉDIO } \\ \text { RISCO BAIXO } & \square & \text { RISCO MAIOR }\end{array}$

(probabilidade de que o indivíduo sofra algum dano como consequência imediata ou tardia do estudo)

4.DURAÇÃO DA PESQUISA : 2 anos 


\section{III - REGISTRO DAS EXPLICAÇÕES DO PESQUISADOR AO PACIENTE OU SEU REPRESENTANTE LEGAL SOBRE A PESQUISA CONSIGNANDO:}

Gostaria de avaliar a audição de adultos com Esclerose Multipla para verificar se esta população apresenta problemas auditivos. Utilizarei testes que avaliam a audição. Antes de realizar a avaliação, serão feitas perguntas sobre as queixas auditivas e dados de identificação. As avaliações serão realizadas primeiramente em uma cabine, onde você irá escutar alguns apitos por meio de fones no ouvido e deverá levantar a mão toda vez que escutar o som. Depois será introduzida uma pressão no ouvido por meio de uma sonda e em seguida apitos na qual você deverá ficar em silêncio parm a obtenção dos resultados. Logo após, serão colocados alguns fios na superfície da pele que serão fixados com esparadrapo, para captar as ondas cerebrais relacionadas à audição. Os testes utilizados não oferecem nenhum risco ou desconforto. 0 benefício dessa avaliação é verificar a sua audição, observando se existe algum problema auditivo que possa estar interferindo na sua comunicação. Você terá a liberdade de retirar seu consentimento a qualquer momento e de deixar de participar do estudo, sem que isto traga prejuízo à continuidade da assistência.

\section{IV - ESCLARECIMENTOS DADOS PELO PESQUISADOR SOBRE GARANTIAS DO SUJEITO DA PESQUISA CONSIGNANDO:}

Os testes realizados para a avaliação da audição são aplicados de forma simples e rápida, sem dor ou desconforto. Caso seja identificado desconforto, o exame será suspenso imediatamente.

As informações e conclusões obtidas por meio deste estudo serão utilizadas para discussōes junto aos pesquisadores, alunos e profissionais da área de fonoaudiologia e áreas afins, não sendo revelado a sua identidade.

Você terá a liberdade de retirar seu consentimento a qualquer momento e de deixar de participar do estudo, sem que isto traga prejuízo à continuidade da assistência.

O pesquisador coloca-se à disposição tanto para os esclarecimentos que se fizerem necessários quanto para o fornecimento de informações relativas aos resultados dos procedimentos aplicados através dos telefones (011) 3091-7452/9144-4240/ (61) 3443-5549/9941-5379 . 


\section{INFORMAÇ̃̃ES DE NOMES, ENDEREÇOS E TELEFONES DOS RESPONSÁVEIS PELO ACOMPANHAMENTO DA PESQUISA, PARA CONTATO EM CASO DE INTERCORRÊNCIAS CLÍNICAS E REAÇÕES ADVERSAS.}

Em caso de dúvida favor entrar em contato com:

Fga. Caroline Rondina Salzano de Oliveira

Endereço: SEPS 709. BI F sala315 - Ed. Biocenter

End. residencial: SQN 212 BI J apt² 201 - Asa Norte

Tel. Residencial: 3347-5379

e-mail: carolinesalzano @ terra.com.br

Dra Carla Gentile Matas (orientadora responsável)

Endereço: Rua Cipotânea 51 Cidade Universitária, Tel. 3091-7452

End. residencial: Av. Divino Salvador, 107 apto 32 - Planalto Paulista

Tel. Residencial: 50512217

e-mail: cgmatas@ usp.br

VI. OBSERVAÇÕES COMPLEMENTARES:

\section{VII - CONSENTIMENTO PÓS-ESCLARECIDO}

Declaro que, após convenientemente esclarecido pelo pesquisador e ter entendido o que me foi explicado, consinto em participar do presente Protocolo de Pesquisa

Brasilia, de de 20 


\section{Referências Bibliográficas}




\section{REFERÊNCIAS BIBLIOGRÁFICAS}

Bergamaschi R, Romani A, Zappoli F, Versino M, Cosi V. MRI and Brainstem Auditory Evoked Potential Evidence of Eighth Cranial Nerve Involvement in Multiple Sclerosis. American Academy of Neurology 1997 Jan 48(1):270-2

BUREAU INTERNATIONAL D'AUDIOPHONOLOGIE. Audiometric classification of hearing impairment: recomentadation 02/1,2003. Disponível em: http://www.biap.biapnglais/rec021.eng.htm.

Callegaro D, Lolio CA Radvany J, Tilbery CP Mendonça RA, Melo AC. Prevalence of multiple sclerosis in city of São Paulo, Brazil in 1990. Neuroepidemiology 1992;11:11-14

Celebisoy, N.; Aydogdu, I.; Ekmekci, O.; Akurekli, O. Middle latency auditory evoked potentials (MLAEPS) in (MS). Acta Neurologica Scandinavica 1996 May 93(5):318-21

Chiappa KH. Principles of evoked potentials. In Chiappa KH. Evoked Potentials in clinical medicine. Philadelphia: Lippncott-Raven Publishers;1997. p. 1-30.

Colafêmina JF, de Fellipe ACN, Junqueira CAO, Frizzo ACF. Potenciais Evocados Auditivos de longa latência (P300) em adultos jovens saudáveis: um estudo normativo. Rev Bras Otorinolaringol. 2000;66(2):144-8.

Collard M, Conraux C, Warter ST. Les dónnes coclheovestibilaires aux differents stades de la sep. A porpos de cent cas. Revue Otoneuroophtalmo 1969;41:374-78.

Cone-Wesson B, Wunderlich J. Auditory evoked potentials from the cortex: audiology applications. Otolaryngol Head Neck Surg. 2003;11(5):372-7. 
Davis h, Davis PA, Loomis AL Havervey PN, Hobart G. Eletrical Reactions of the human brain to auditory stimulation during sleep J. Neurophysiol 1939; 2:500-14.

Dijk JG, Jennekens-Schikel A, Caekebeke JFV, Singh A, Zwinderman $\mathrm{AH}$. What is the validity of an "abnormal" evoked or event-related potential in MS. The J Neurol Sci 1992;109:11-7.

Donchin E, Ritter W, McCallum WC. Cognitive psychophysiology: the endogenous components of an "abnormal" evoked or event-related potential in MS. The Journal of the Nerological Sciences 1992;109:11-17.

Durrant JD, Ferraro JA. Potenciais auditivos evocados de curta latência: eletrococleografia e audiometria de tronco encefálico. In: Musiek FE, Rintelmann WF. Perspectivas atuais em avaliação auditiva. São Paulo: Ed. Manole; 2001. P.193-238.

Ferraro JA, Durrant JD. Potenciais Auditivos Evocados: Visão geral e princípios básicos. In: Katz J, org. Tratado de Audiologia Clínica. $4^{a}$ ed. São Paulo: Manole; 1999. p.315-35.

Fischer JS. Cognitive impairment in multiple sclerosis. In:Cook SD. Handbook of Multiple sclerosis. New York: Marcel Dekker, Inc;2001. p.23355.

Fisher C, Joyeux O, Haguenauer JP, Mauguiere F, Schott B. Surdité et acouphenes lors de poussées dans 10 cas de sclérose en plaques Revue Neurol 1984;140:117-25.

Frizzo ACF, Alves RPC, Colafêmina JF. Potenciais evocados auditivos de longa latência: um estudo comparativo entre hemisférios cerebrais. Rev Bras Otorinolaringol. 2001;67(5).

Geisler C, Frishkopf L, Rosenblith W. Extracranial responses to acoustic clicks in man. Science. 1958;128:1210-11. 
Giesser BS, Schroeder MM, LaRocca NG, Kurtzberg D Ritter W, Vaughan HG, Scheinberg LC. Endogenous event-related potentials in multiple sclerosis patients. Eletroenceph Clin Neurophisiol 1992;82:320-29.

Gil R, Zai L, Neau JP, Jonveaux T, Agbo C, Rosolacci, T, Burbaud P, Ingrand $P$. Event-related auditory evoked potentials and multiple sclerosis. Eletroenceph Clin Neurophysiol 1992; 88:182-7

Gonzales-Rosa JJ,Vazquez-Marrufo M, Vaquero E, Duque P, Borges $M$, Gamero MA, Gomez MC, Izquierdo G. Diferential Cognitive impairment for diverse forms of multiple sclerosis Bmc Neuroscience 2006 7;39

Hall III JW. Handbook of auditory evoked potencial. 1992. Boston Allyn and Bacon.

Hood LJ. Estimating auditory function with auditory evoked potentials. The hearing journal. 1995;48(10):32-42.

Hillyard AS, Picton TW. Electrophysiology of cognition. In: Plum F. Handbook of physiology. Maryland: Betmesda; 1987. p.519-84.

Jerger J, Jerger S. Alterações auditivas: um manual para avaliação clínica. São Paulo: Atheneu 1989.

Jerger JF, Oliver TA, Rivera VM. Patterns of auditory abnormality in multiple sclerosis Audiology 1986;25:193-209.

Junqueira CAO, Frizzo ACF. Potenciais evocados auditivos e curta, média e londa latência. In: Aquino AMCM, org. Processamento auditivo Eletrofisiologia e Psicoacústica. São Paulo: Lovise; 2002. p.63-85.

Kraus N, Kilehy $P$, McGee T. Potenciais evocados de média latência (MLR). In: Katz J. Tratado de audiologia Clínica. 4Ed. São Paulo: Manole 1999; p.384-402.

Kraus N, McGee T. Potenciais evocados auditivos de longa latência. In: Katz J. Tratado de audiologia Clínica. 4Ed. São Paulo: Manole 1999; p.403-420. 
Kurokawa T, Kira J, Tobimatsu S. Electrophysiolgical diagnosis for multiple sclerosis. Nippon Rinsho. 2003 Aug;61(8):1347-54.

Landete-PL, Casanova BE Deterioração cognitiva, formas clínicas e progressão na Esclerose Múltipla. Rev. Neurol. 2001;32:884-887

Lublin FD, Reingold SC. Defining the clinical course of multiple sclerosis: resilts of international survey. Neurology 1996;46:907-11.

Magnano I, Aiello I, Piras, MR. Cognitive impairment and neurophysiological correlates in MS Journal of the Neurological Sciences. 2006 245(1-2, Sp. Iss. SI): $117-122$

Martyn C. The epidemiology of multiple sclerosis. In: Matthews WB. McAlpime's multiple sclerosis. 2Ed. New York: Chruchill Livingstone 1991;3:42.

Matas CG, Frazza MM, Munhoz MLL. Aplicação do potencial auditivo de tronco encefálico em audiologia pediátrica. In: Basseto $M C$, Brock $R$, Wajnsztejn R. Neonatologia: Um convite a atuação fonoaudiológica. São Paulo: Lovise 1998; p.411-437.

Melaragno Filho R. Esclerose Múltipla: manual para pacientes e suas famílias. São Paulo: ABEM (Associação Brasileira de Esclerose Múltipla) 1992.

Möller AR, Jannetta $P$, Bennett $M$, Möller MB. Intracranially Recorded Responses from Human Auditory Nerve: new insights into the oringin of brainstem Evoked Potencials. Eletroencephalography and Clinical Neurophysiology, 1981;52:18-27.

McPherson DL. Late potencials of the auditory system (evoked potencials). Singular Press. Cidade. 1996.

Munhoz MSL, Silva MLG, Ganança MM, Caovilla HH, Frazza MM. Respostas auditivas de longa latência. In: Munhoz MSL, Caovilla $\mathrm{HH}$, Silva MLG, Ganança MM. Audiologia Clinica. São Paulo: Atheneu; 2000.p.231-42. 
Mustillo P. Auditory deficits in multiple sclerosis: a review. Audiology 1984;23:145-64.

Musiek FE, Geurkink N. Auditory Brainstem and Middle Latency Evoked Response Sensitivity near threshold. Ann Otol Rhinol Laringol. 1981;90:23640.

Musiek FE, Bornstein S. Contemporary Aspects of diagnostic Audiology. Am J Otolaryngol. 1992;13(1):23-33.

Musiek FE, Borenstein SP, Hall III JW, Schwaber MK. Audiometria de tronco encefálico (ABR): neurodiagnóstico e aplicações intra-operatórias. In: Katz J, org. Tratado de Audiologia Clínica. $4^{a}$ ed. São Paulo: Manole; 1999. p.349 71.

Musiek FE, Lee WW - Potenciais auditivos de média e longa latência - In: Perspectivas Atuais em Avaliação Auditiva - Org. MusieK, FE \& Rintelmann, WF. Editora Manole. Barueri. São Paulo. 2001. p.239-67

Newton MR, Barret G, Callanan MM, Towell AD. Cognitive event-related potentials in multiple sclerosis. Brain 1989;112:1637-960.

Noffsinger D, Olsen WO, Carhart R, Hart CW, Sangal V. Auditory and vestibular aberrations in multiple sclerosis Acta OtoLaryngol 1972;303:05-63.

Oliveira EML, Oliveira ASB, Gabbai AA. Estudo clínico de 50 pacientes acompanhados no ambulatório de neurologia UNIFESP - EPM. Arq Neuropsiquiatr 1999;57:282-89.

Özdamar Ö, Kraus N. Auditory middle-latency responses in humans. Audiology. 1983; 22: 34-49.

Picton TW, Hillyard AS, Kraus HI, Galambos R. Human auditory evoked potentials. Electroencephalor Clin Neurophysiol. 1974; 36: 179-90.

Picton TW. The P300 wave of the human event-related potential. J. Clin Neurophysiology 1992;09:465-479. 
Polich J. P300 in clinical applications: meaning, method, and measurement. Am J EEG Technol. 1991;31:201-31.

Rao SM, Leo GJ, Bernardin L, Unverzagt F. Cognitive dysfunction in multiple sclerosis. Neurology 1991;34:694-702.

Ruth RA, Lambert PR. Auditory evoked potentials. Otolaryngol Clin North Am. 1991;24(2):349-70.

Russo NM, Nicol TG, Zecker SG, Hayes EA, Kraus N. Auditory training neural timimg in the human brainstem. Behav Brain Res. 2005; 156: 95-103.

Santos EC, Yokota M, Dias NF. Multiple sclerosis: study of patients with relapsing-remitting form registered at Minas Gerais Secretary of State for Health. Arq Neuropsiquiatr. 2007; 65(3B):885-8.

Santos MAR, Lana Peixoto MA, Munhoz MSL, Almeida AV. Avaliação dos potenciais evocados auditivos do tronco encefálico na Esclerose Múltipla. Arq Neuropsiquiatr 2003; 61(2-B): 392-97.

Santos MAR, Munhoz MSL, Peixoto MAL, Haase VG, Rodrigues LJ, Resende LM Contribuição do Mismatch Negativity na avaliação cognitiva de indivíduos portadores de Esclerose Múltipla. Rev. Bras. Otorrinol 2006, 72 (6) 800-08

Schochat E. Potenciais evocados auditivos. In: Carvallo RMM. Fonoaudilogia Informação para a formação: Procedimentos em Audiologia. Rio de Janeiro: Guanabara Koogan; 2003. p.57-70.

Schochat E. Avaliação eletrofisiológica da audição. In: Ferreira LP, BefiLopes D, Limongi SCO, org. Tratado de fonoaudiologia. São Paulo: Rocca; 2004. p.656-68.

Schochat E, Rabelo CM, De A Loreti R C. Sensitividade e especificiadade do potencial de média latência. Rev Bras Otorinolaringol. 2004;70(3):353-8. 
Schochat E, Matas CG, Sanches SGG, Carvallo RMM, Matas S. Central Auditory evaluation in multiple sclerosis Arq Neuropsiquitr 2006:64(3-B):872876.

Simpósio de Atualização Sobre Esclerose Múltipla. Jornal Interno da Associação Brasileira de Esclerose Múltipla (ABEM), 1995.

Singhal A, Fowler B.The differential effects of Sternberg short- and long-term memory scanning on the late $\mathrm{Nd}$ and $\mathrm{P} 300$ in a dual-task paradigm. Brain Res Cogn Brain Res. 2004 ;21(1):124-32.

Sutton S, Braren M, Zubin J, John ER. Evoked potential correlates of stimulus uncertainty. Science. 1965;150:1187-8. 